\title{
DETERMINANTES DO APROVEITAMENTO FINAL DE PONTOS DAS EQUIPES NOS CAMPEONATOS BRASILEIRO E ARGENTINO DE FUTEBOL
}

\author{
Jacy de Freitas Alves* \\ Jader Fernandes Cirino ${ }^{\dagger}$ \\ Francisco Carlos da Cunha Cassuce $\ddagger$
}

\begin{abstract}
Resumo
O estudo analisa os determinantes do aproveitamento percentual de pontos dos times ao final dos campeonatos brasileiro e argentino de futebol da primeira divisão no período 2006-2017. Através da regressão beta, verificou-se que o valor de mercado médio dos jogadores da equipe, entendido como proxy da qualidade do elenco, e a manutenção do mesmo treinador ao longo do campeonato foram cruciais para o melhor desempenho dos clubes nas duas ligas. Portanto, visando aumento de receitas para os clubes na forma de premiação e venda de ingressos, produtos licenciados e programas de sócio-torcedor, os gestores devem considerar fortemente tais variáveis.
\end{abstract}

Palavras-chave: futebol, desempenho, campeonato nacional, Brasil, Argentina.

\begin{abstract}
The study analyzes the determinants of percentage points achievement of the teams at the end of the Brazilian and Argentine first division soccer championships in the period 2006-2017.Through beta regression, it was found that the average market value of the team players and the maintenance of the same coach throughout the championship were crucial for the better performance of the clubs in the two leagues. Therefore, in order to increase revenue for clubs in the form of awards and sales of tickets, licensed products and partner-fan programs, managers should strongly consider such variables.
\end{abstract}

Keywords: soccer, performance, national championship, Brazil, Argentina. JEL classification: Z20, L21, M21

DOI: http://dx.doi .org/10.11606/1980-5330/ea154821

\footnotetext{
* Universidade Federal de Viçosa (UFV), Brasil. E-mail: jacyalves29@gmail.com

† Universidade Federal de Viçosa (UFV), Brasil. E-mail: jader.cirino@ufv.br

‡ Universidade Federal de Viçosa (UFV), Brasil. E-mail: francisco.cassuce@ufv.br
} 


\section{Introdução}

O futebol é o esporte mais popular do mundo (Hoffmann et al. 2002, Papanikos 2017) em razão de fatores como seu alto grau de imprevisibilidade e regras de fácil entendimento, fazendo com que ele seja acompanhado de perto por milhões de pessoas ao redor do planeta (Aidar \& Faulin 2013). De acordo com dados da Federação Internacional de Futebol (FIFA), citados por Conmebol (2013), o futebol já contava, em 2006, com 265 milhões de jogadores e jogadoras profissionais em atividade em todo o planeta, além de 5 milhões de árbitros e funcionários. Tais números contribuem para a difusão da atividade na indústria do entretenimento, possibilitando a abertura de novos mercados no mundo dos negócios. Além disso, Ribeiro \& Lima (2012) apontam que o esporte vem passando por uma transformação tanto institucional quanto gerencial, onde os clubes deixaram de ser simples organizações esportivas para se tornarem grandes empreendimentos, com elevadas receitas associadas principalmente ao alto preço dos ingressos, transferências de jogadores, premiação das competições e direitos de imagem.

No Brasil, o futebol pode ser considerado uma identidade cultural do povo e, mais que isso, um modelo de expressão da sociedade brasileira. Isso porque tal esporte demanda estilo de jogo e exigência técnica que se encaixam nas características socioculturais da população brasileira, de modo que as pessoas se identificam com situações e emoções ocorridas dentro de campo. O futebol é uma maneira do povo brasileiro extravasar emoções profundas como paixão, ódio, prazer, alegria, tristeza, força e muitas outras (Daolio 2000, Guedes 2014).

Essa identidade cultural com o futebol não é muito diferente na Argentina. Apesar de nos primeiros anos, o futebol ter sido uma atividade elitista, apenas de ingleses, com o passar do tempo as raízes latinas no país prevaleceram para que o referido esporte se tornasse paixão nacional, principalmente depois que os primeiros times trocaram seus nomes ingleses por outros mais próximos da cultura argentina. Cicciaro \& Puccio (2010) e Guedes (2014) mencionam que o futebol na Argentina alcançou tamanha identificação com o povo que o mesmo é capaz de construir amizades ou causar lutas agressivas entre os torcedores que vão até as últimas consequências para defender seu time de futebol. Em sua pesquisa, Cicciaro \& Puccio (2010) afirmam que 70\% dos torcedores entrevistados já se envolveram pelo menos uma vez em atos violentos em caso de derrota do seu clube de coração. Ademais, no período 2008-2017, a média anual de 9 torcedores mortos em virtude da violência relacionada ao futebol na Argentina foi maior do que a verificada, por exemplo, no auge da violência entre as torcidas na Inglaterra, que fora de 6 entre o período 1974-1989 (Trejo et al. 2019).

Assim, percebe-se que o significado do futebol na Argentina é tamanho que o mesmo deixou de ser apenas atividade de entretenimento para se tornar fator que interfere na personalidade das pessoas e no relacionamento cultural das mesmas com a sociedade.

No Brasil, o setor de esportes representou em 2012, aproximadamente, $1,6 \%$ do PIB do país, sendo o futebol responsável por 53\% do total produzido pelo ramo em questão. Em termos quantitativos, cerca de $0,8 \%$ do PIB brasileiro foi composto pelo futebol. Este montante está relacionado às transações entre clubes, entidades esportivas, mídia, comércio, vestuário, artigos e equipamentos, dentre outros. Além dessas atividades, indiretamente, o setor tem 
impacto nas indústrias de alimentação, transporte, hotelaria e comunicação (Pluri Consultoria 2012).

Na economia argentina, o futebol também possui importante impacto econômico, representando cerca de 1,3\% do PIB do país em 2013. Tal produção equivale não apenas aos clubes, mas também aos setores que fazem parte da cadeia que é ligada diretamente ao futebol como as empresas de publicidade, comunicação, turismo, bilheteria e exportação de atletas (Coremberg et al. 2015).

Diante do contexto em que os clubes da primeira divisão, tanto do campeonato brasileiro quanto do argentino, têm papel altamente relevante na produção do setor futebol em seus respectivos países, já que são os detentores da maior parte das transações financeiras no futebol local, faz-se necessário entender quais os aspectos relevantes na determinação do desempenho das equipes em suas ligas nacionais. Tal análise permitirá que as agremiações busquem alternativas para melhorar o desempenho dentro de campo e, consequentemente, fora dele, pois um desempenho satisfatório na liga nacional gera aumento de receitas, principalmente com premiação e venda de ingressos e programas de sócio-torcedor.

Este aumento nas receitas possibilita maior capacidade de investimento no futebol e, assim, torna-se viável a montagem de elencos mais fortes, elevando a competitividade nos torneios. Como resultado, tem-se maior comprometimento da torcida, o qual se reflete na elevação de público nos jogos, aumento das cotas de sócio-torcedor e da compra de produtos licenciados com a marca do clube, gerando deste modo, um ciclo virtuoso (Pluri Consultoria 2014a).

Sendo assim, este trabalho tem por finalidade abordar quais são os principais determinantes do desempenho dos clubes, em termos do aproveitamento percentual relacionado ao número de pontos ao final do torneio, nos campeonatos brasileiro e argentino da primeira divisão no período entre 2006 e 2017. O intervalo de tempo escolhido para análise foi este porque a partir de 2006 é possível obter as informações para todos os clubes participantes da amostra, ao passo que 2017 é o ano em que se teve os campeões nacionais mais recentes quando da elaboração do estudo.

A escolha das ligas nacionais de Brasil e Argentina se deve primeiro ao fato de que as duas são as únicas da América do Sul que estavam, segundo a Pluri Consultoria (2014b), entre as 15 mais valiosas do mundo em termos de valor de mercado dos elencos para as temporadas de 2012, 2013 e 2014. Ademais, até o ano de 2017, os clubes dos dois países eram responsáveis por mais de $70 \%$ dos títulos da Libertadores da América, a principal competição continental da América do Sul, o que torna este um diferencial a mais para a escolha das duas ligas nacionais.

Em termos de contribuição para a Economia do Esporte, a pesquisa traz abordagem inédita e atual sobre o tema no Brasil e na Argentina, a qual pode fornecer subsídios para a ação dos agentes ligados ao esporte profissional nos países em questão.

A hipótese central desta pesquisa é que o valor de mercado médio dos jogadores, assim como verificado por Gerhards \& Mutz (2017) para as principais ligas de futebol europeias, é o principal fator determinante para a classificação final nos campeonatos brasileiro e argentino de futebol, uma vez que tal medida é considerada como característica principal para mensurar a qualidade dos elencos. Acredita-se, portanto, que possuir um elenco valioso, de modo geral, eleva o aproveitamento dos clubes ao fim do torneio. Além do valor de mercado, o estudo analisa o impacto das seguintes variáveis para o sucesso 
nas duas principais ligas sul-americanas: flutuação do elenco, desproporção do valor de mercado entre os atletas do mesmo plantel, presença de jogadores estrangeiros, coeficiente de variação da idade do elenco, recém-promoção da segunda divisão, número de jogos simultâneos à liga em outras competições e quantidade de treinadores ao longo do campeonato.

Dessa forma, o objetivo geral do artigo é identificar variáveis que interferem no aproveitamento final, dado em percentual de pontos ganhos em relação ao total de pontos disputados, nas ligas brasileira e argentina de futebol. Especificamente, busca-se comparar os campeonatos nacionais do Brasil e Argentina, apontado suas principais diferenças e pontos em comum.

\section{Revisão de Literatura}

Essa seção apresenta trabalhos seminais sobre a Economia do Esporte e estudos empíricos voltados para o futebol relacionados ao tema do presente artigo.

Entre o primeiro grupo de trabalhos, o estudo de Sloane (1971) é o único que trata do futebol inventado pelos ingleses, onde a criação e estrutura dos clubes de futebol é dada de forma diferente da que é feita pelas equipes dos esportes norte-americanos que são criados como empresas visando principalmente obter lucro. Dessa forma, o referido autor fornece subsídios para esta pesquisa, na medida em que considera que os clubes buscam maximizar, além do lucro, a utilidade da instituição.

A maximização da utilidade, dependendo de seu grau, pode exigir uma restrição mínima nos lucros. Esta discussão acerca da maximização do lucro no esporte teve início com as obras de Rottenberg (1956), Neale (1964) e Jones (1969), onde os mesmos discutem, para os esportes norte-americanos, quais seriam os agentes maximizadores e quais ações seriam as mais adequadas para que o ator em questão alcançasse seus objetivos. Diferente destes autores, Sloane (1971), analisando o caso do futebol inglês, acredita que o pressuposto da maximização da utilidade pode fornecer previsões mais válidas que o da maximização de lucro não só nos esportes profissionais, mas também em outras formas de entretenimento.

Adicionalmente à esta discussão existente na origem dos trabalhos acerca da Economia do Esporte sobre o que os clubes maximizam, Fort \& Quirk (2004) e Késenne (2006) debatem sobre a diferença na escolha por jogadores talentosos entre as ligas onde os clubes maximizam o percentual de vitórias, caso das ligas europeias de futebol, para as ligas em que os proprietários das equipes visam lucro, caso das ligas esportivas norte-americanas. Fort \& Quirk (2004) afirmam que no primeiro caso, o preço e a demanda pelos atletas mais talentosos é pelo menos tão grande quanto na segunda situação. Dessa forma, apesar de participar de ligas em que o foco de maximização é distinto, os proprietários têm que arcar com, no mínimo, o mesmo ônus para adquirir os melhores atletas e maximizar seus objetivos.

Késenne (2006) pondera ainda que a maximização do percentual de vitórias só seria possível se os clubes maximizassem a quantidade de jogadores talentosos em suas equipes. Ao comparar os dois tipos de maximização, o autor expõe que existem diferenças na composição do mercado de atletas em ambos os casos, já que nas ligas onde os clubes visam maximizar as vitórias há maior mobilidade internacional de jogadores do que nas ligas onde as equipes visam maximizar os lucros. Assim, o estudo conclui que nas ligas cujo foco dos 
clubes é a maximização das vitórias, a demanda por atletas talentosos é maior e sua distribuição é mais desigual do que nas ligas cujo objetivo é maximizar os lucros.

Retomando o trabalho de Sloane (1971), o estudo aponta que a questão da maximização da utilidade se refere ao fato de que o clube, diferente de uma empresa, se enquadra mais em um sistema unitário do que em um sistema pluralista de interesses divergentes. Isso porque como o que é julgado na indústria do futebol é o desempenho do time, o objetivo de todos os membros do clube é o sucesso dentro de campo e não o lucro. A lealdade dos torcedores e diretores ao clube por si só produz utilidade, de modo que estes estão dispostos a doar dinheiro visando obter sucesso dentro do campo. Portanto, o empresário ligado a um time de futebol, ao investir nele, busca maximizar também sua própria utilidade.

No futebol brasileiro e argentino, os clubes, em sua fundação, não tinham o propósito de se tornar grandes empreendimentos lucrativos, mas sim buscar ter uma instituição que pudesse, na prática do esporte, representar um bairro, cidade ou uma camada da população. Prova disso é que, diferente do que aconteceu na Inglaterra, onde o futebol é profissionalizado desde 1896, no Brasil e Argentina o esporte passou por uma fase amadora, onde a prática era dada simplesmente com o intuito de entreter e os clubes eram pautados em uma gestão coletiva baseada em uma composição jurídica de associação civil sem fins lucrativos (Gil 2003).

Portanto, ao mencionar que a maximização da utilidade pode ser o principal foco de um clube, acredita-se que esta assertiva se encaixa melhor na realidade vivida pelos clubes brasileiros e argentinos, visto que a profissionalização da gestão do futebol buscando melhorar os resultados financeiros da instituição se deu em um período relativamente recente se comparado ao futebol inglês. Destaca-se, também, que no futebol brasileiro e argentino existem agentes que investem nos clubes com o intuito de maximizar sua própria satisfação, na medida que, ao aumentar o investimento no clube de coração, eleva-se a possibilidade de o investidor vê-lo campeão.

A ação de agentes financeiros no Brasil, como Leila Pereira e Paulo Nobre no Palmeiras, e na Argentina, como Marcelo Tinelli no San Lorenzo, são exemplos de empresários que participam diretamente da vida financeira do clube ajudando em contratações e prêmios. Nesses casos, a relação com o time vai além do simples objetivo de obter ganhos financeiros, pois eles também visam maximizar sua própria utilidade na medida que, a partir do financiamento particular, buscam ver a equipe para qual torcem sempre no mais alto nível possível. Ademais, muitas das vezes tais agentes tem interesse em desempenhar cargos políticos dentro dos clubes, sendo o caso dos três citados.

Passando-se para estudos empíricos relacionados ao desempenho esportivo das equipes de futebol, tem-se que os condicionantes microeconômicos estariam ligados a elementos técnicos, estruturais e psicológicos dos clubes, tais como qualidade do elenco, mando de campo, estratégia na partida e apoio da torcida. Palomino et al. (1998), através da união de teoria dos jogos com análise econométrica, usaram tais variáveis como suporte para observar como essas características alterariam a probabilidade de marcar gols dos times de futebol da Itália, Inglaterra e Espanha para as temporadas de 1995 a 1998. Como resultado, os autores afirmam que os elementos utilizados são conjuntamente importantes para a referida probabilidade.

Os determinantes macroeconômicos estão relacionados a aspectos gerais 
da economia em que os clubes se enquadram, tais como o PIB per capita, taxa de desemprego, tamanho da população, fator geográfico e origem cultural da localidade em que o clube tem sua sede. Hoffmann et al. (2002) fizeram um estudo com esse foco para identificar a conexão que existe entre o nível de desenvolvimento de uma nação e o sucesso no futebol. Para tanto, usaram o aporte econométrico tendo como variável dependente o número de pontos no ranking FIFA para o ano de 2001. Os resultados mostraram que o fato do país ser latino, o PIB per capita e o fator geográfico são condicionantes significativos para o desempenho de uma seleção no referido ranking.

Gerhards \& Mutz (2017) analisaram os fatores que impactaram no sucesso dos clubes nas ligas nacionais europeias, onde aspectos como o valor de mercado do time, desproporção de valor de mercado dos atletas, diversidade cultural e grau de flutuação dentro do elenco foram usados como variáveis para determinar o desempenho, em termos de pontuação, ao final das competições nacionais. Para tal aferição, abrangeu-se as temporadas de 2011/12 a 2015/16 para as 12 principais ligas nacionais da Europa. De modo geral, os autores afirmam que o sucesso no futebol profissional é fruto principalmente do nível de investimento financeiro em elenco, já que, segundo os mesmos, 2/3 da variância no desempenho da equipe depende do valor de mercado dos jogadores.

$\mathrm{Na}$ literatura brasileira, existem estudos que relacionam a questão dos determinantes econômicos com o desempenho das equipes em competições nacionais, assim como outros fatores que interferem na competitividade e equilíbrio do esporte no Brasil.

Araújo Jr et al. (2005) utilizaram em sua pesquisa variáveis socioeconômicas e políticas para determinar o desempenho dos clubes de cada estado no campeonato brasileiro de futebol no período de 1971 a 1998. De modo geral, os autores inferem que a ação política dos dirigentes das federações e dos clubes interferiu negativamente na probabilidade de sucesso das equipes na liga nacional, ao passo que a renda per capita do estado impactou positivamente nas chances de uma equipe de determinado estado ser bem-sucedida no torneio.

Buscando realizar uma análise de como mudanças institucionais no futebol brasileiro interferiram na competitividade da liga, Drummond et al. (2010) discutiram de que forma tais mudanças, como a criação da Lei Pelé e a alteração do formato de disputa e da quantidade de times participantes, modificaram o equilíbrio competitivo do torneio. Em suma, afirmam que as reformulações no formato do campeonato foram benéficas para o aumento da competitividade da liga nacional.

Complementando esta questão do equilíbrio competitivo da liga brasileira, Gasparetto \& Barajas (2016) concluem em seu trabalho que, comparativamente, o campeonato brasileiro é mais equilibrado do que as principais ligas europeias de futebol. Os autores, assim como Drummond et al. (2010), utilizaram os índices de balanço competitivo Herfindahl e C4 para inferir sobre o tema supracitado.

Importante destacar que os textos econômico-científicos sobre futebol no Brasil ainda são incipientes, haja vista a reconhecida popularidade nacional do esporte. Nesse sentido, Drummond et al. (2010) colocam que somente a partir dos anos 2000 começaram a surgir mais pesquisas sobre o tema. Além dos três estudos já citados anteriormente, enquadram-se nessa perspectiva os trabalhos de Giovannetti et al. (2006), Madalozzo \& Villar (2009), Araujo Jr 
et al. (2018), Shikida, Carraro \& Júnior (2018) e Shikida, Araujo Jr \& Pinho (2018).

Diante do apresentado, o presente estudo faz uma adaptação do trabalho de Gerhards \& Mutz (2017) para o continente sul-americano, enfatizando os campeonatos brasileiro e argentino de futebol. Diferente dos outros trabalhos citados anteriormente, esta pesquisa busca fazer uma análise das ligas nacionais de Brasil e Argentina comparando as mesmas e considerando variáveis que ainda não haviam sido levadas em conta conjuntamente em estudos anteriores.

\section{Metodologia}

O presente estudo analisa os determinantes para o aproveitamento final de pontos dos clubes participantes dos campeonatos da primeira divisão do futebol brasileiro e argentino no período entre 2006 e 2017. Para essa situação na qual a variável de resposta $y$ é medida continuamente no intervalo $0<y<1$, Ferrari \& Cribari Neto (2004) propuseram a classe de modelos de regressão beta ${ }^{1}$. Conforme os autores, tais modelos são baseados na hipótese adequada de que a variável de resposta é beta distribuída, uma vez que a distribuição beta é bastante flexível para modelar proporções como a proposta no presente estudo.

A densidade beta é dada por:

$$
\pi(y ; p, q)=\frac{\Gamma(p+q)}{\Gamma(p) \Gamma(q)} y^{p-1}(1-y)^{q-1}, 0<y<1
$$

onde $p>0, q>0$ e $\Gamma($.) é a função gama conforme segue:

$$
\Gamma(p)=\int_{0}^{\infty} y^{p-1} e^{-y} d y
$$

A média e a variância de $y$ são, respectivamente:

$$
\begin{gathered}
E(y)=\frac{p}{(p+q)} \\
\operatorname{var}(y)=\frac{p q}{(p+q)^{2}(p+q+1)}
\end{gathered}
$$

O procedimento de estimação de $p$ e $q$ por máxima verossimilhança é apresentado por Cribari Neto \& Vasconcellos (2002).

Uma vez que a modelagem econométrica geralmente considera a média da variável de resposta, Ferrari \& Cribari Neto (2004) sugerem uma reparametrização da densidade beta, na qual $\mu=p /(p+q)$ e $\phi=p+q$, ou seja, $p=\mu \phi$ e $q=(1-\mu) \phi$. Dessa forma, as equações (3) e (4) tornam-se, respectivamente,

\footnotetext{
${ }^{1} \mathrm{~A}$ apresentação dos modelos de regressão beta é largamente baseada em Ferrari \& Cribari Neto (2004).
} 
$E(y)=\mu$ e $\operatorname{var}(y)=\frac{V(\mu)}{1+\phi}, \operatorname{com} V(\mu)=\mu(1-\mu)$. Assim, a função densidade beta passa a ser representada conforme segue:

$$
f(y ; \mu, \phi)=\frac{\Gamma(\phi)}{\Gamma(\mu \phi) \Gamma((1-\mu) \phi)} y^{\mu \phi-1}(1-y)^{(1-\mu) \phi-1}, 0<y<1
$$

onde $0<\mu<1$ e $\phi>0$.

Dependendo dos valores dos dois parâmetros da equação (5), a distribuição beta torna-se bastante flexível para modelar proporções, já que a mesma acomoda distribuições simétricas, assimétricas, em formas de J e de J invertido a partir de diferentes combinações dos referidos parâmetros.

Sendo $y_{1}, \ldots, y_{n}$ variáveis independentes aleatórias, onde cada $y_{t}, t=1, \ldots, n$, segue a distribuição de densidade da equação (5) com média $\mu_{t}$ e parâmetro de precisão desconhecido $\phi$, tem-se o seguinte modelo, admitindo que a média de $y$ pode ser representada conforme segue:

$$
g\left(\mu_{t}\right)=\sum_{i=1}^{k} x_{t i} \beta_{i}=\eta_{t}
$$

onde $\beta=\left(\beta_{1}, \ldots, \beta_{k}\right)^{T}$ é um vetor de parâmetros e $x_{1}, \ldots ., x_{t k}$ variáveis são as observações das $k$ covariadas $(k<n)$, as quais são assumidas como fixas e conhecidas. Adicionalmente, $g($.) é uma função de ligação estritamente monotônica e duas vezes diferenciável, com domínio em $(0,1)$ e imagem no conjunto dos números reais $\mathbb{R}$.

Para o modelo de regressão beta, é possível utilizar diferentes funções de ligação, como a logit $g\left(\mu_{t}\right)=\log \{\mu /(1-\mu)\}$, a probit $g\left(\mu_{t}\right)=\Phi^{-1}(\mu)$, a cloglog $g\left(\mu_{t}\right)=\log \{-\log (1-\mu)\}$ e a $\log \log g\left(\mu_{t}\right)=-\log \{-\log (\mu)\}$.

De maneira similar, o parâmetro de precisão $\phi$ escala a variância condicional de $y$ por meio da função de ligação de escala $h(\phi)=x \gamma$. Para essa última, podem ser utilizadas as funções $\log h(\phi)=\log (\phi)$, raiz $h(\phi)=\sqrt{\phi}$ e identidade $h(\phi)=\phi$

A estimação do vetor paramétrico k-dimensional $\Theta=\left(\beta^{T}, \phi\right)^{T}$, em que $k=$ $(p+1)$, é feita pelo método da máxima verossimilhança. Destaca-se que os estimadores obtidos serão consistentes e eficientes quando o modelo é corretamente especificado. De acordo Smithson \& Verkuilen (2006), para a regressão beta, o modelo que minimizar o critério de informação bayesiana (BIC) será o de melhor especificação. Dessa forma, no artigo foram estimados doze modelos por meio do software Stata considerando todas as combinações possíveis entre as funções de ligação e as funções de ligação de escala citadas, escolhendo para a análise, conforme procedimento proposto por Cameron \& Trivedi (2005), aquele modelo que minimizar o BIC.

A equação (7) representa a regressão a ser estimada no estudo utilizando separadamente os dados do campeonato brasileiro e do campeonato argentino, obtendo-se assim, dois modelos distintos com a melhor especificação conforme o BIC. A equação geral é apresentada conforme segue: 


$$
\begin{array}{r}
A P R_{i t}=\beta_{0}+\beta_{1} V M_{i t}+\beta_{2} V M_{i t}^{2}+\beta_{3} C V E i t+\beta_{4} E S T R_{i t}+\beta_{5} F L U T_{i t} \\
+\beta_{6} T E C_{i t}+\beta_{7} T E C_{i t}^{2}+\beta_{8} C V I_{i t}+\beta_{9} Q O_{i t}+\beta_{10} Q^{2} O_{i t}^{2}+ \\
\beta_{11} P_{R O M}+\beta_{12} D C L U B_{i t}+\mu_{i t}
\end{array}
$$

onde $i$ se refere à cada unidade de corte transversal da amostra, que neste caso são os times; $t$ é referente aos anos da amostra, que vão de 2006 a 2017; $\beta_{j}$, $(j=$ $0, \ldots, 12)$ são os parâmetros a serem estimados; e $\mu$ é o termo de erro aleatório. A descrição e o detalhamento das variáveis utilizadas são apresentados a seguir.

A variável dependente é dada pelo aproveitamento percentual em número de pontos ao final da liga, pois ao se considerar o campeonato argentino no modelo, deve-se levar em consideração que o mesmo passou por modificações em sua fórmula de disputa no período 2006-2017, fazendo com que o número total de pontos disputados na liga fosse modificado em alguns anos. Portanto, para que haja uma padronização da variável dependente, em todos os modelos é considerado o aproveitamento ao final de cada campeonato e não a quantidade de pontos conquistados ao término do mesmo.

O campeonato brasileiro manteve a mesma fórmula ao longo de todo horizonte temporal da amostra (com 20 clubes, se enfrentando entre si em turno e returno no período de maio a dezembro), sendo campeã a equipe com o maior número de pontos ao final da liga. Já o campeonato argentino, no recorte de 2006 a 2014, era divido em duas competições distintas, realizadas com 20 clubes se enfrentando em turno único, sendo elas o Apertura, disputado no segundo semestre do ano, entre agosto e dezembro, e o Clausura ${ }^{2}$, normalmente jogado entre fevereiro e junho, sendo campeão o time com maior número de pontos em cada um desses torneios. Diante disto, entre 2006 e 2014, considerou-se nesta pesquisa somente os dados referentes ao torneio Apertura, já que era a competição em que o recorte de tempo mais se assemelhava ao do campeonato brasileiro da primeira divisão.

Em 2015, a liga argentina mudou de formato, passando a contar com 30 equipes se enfrentando de fevereiro a dezembro em turno único e com uma rodada extra somente de clássicos, totalizando 30 jogos. No ano de 2016, com o intuito de se adequar ao calendário europeu de disputa (início em agosto e final em junho do ano seguinte, com jogos de ida e volta), houve nova mudança, de modo que no primeiro semestre aconteceu um torneio de transição no qual os 30 times se dividiram em dois grupos com 15 equipes cada, onde cada um jogou um total de 16 partidas. Este campeonato especificamente foi considerado na pesquisa, visto que foi o único que começou e terminou em 2016. Para que este se equiparasse aos demais, levou-se em consideração apenas o desempenho dos times na fase inicial, de forma que foi considerada a performance dos clubes como em um campeonato de pontos corridos convencional. Já para o ano de 2017, foi considerada a recém-criada Superliga Argentina, que contou com 30 clubes que se enfrentaram em turno único, tendo início em agosto de 2016 e término em junho de 2017.

\footnotetext{
${ }^{2}$ Nas temporadas 2012/2013 e 2013/2014, os respectivos campeonatos tiveram os nomes alterados para Inicial e Final. No segundo semestre de 2014, o campeonato argentino foi denominado Torneio de Transição.
} 
Sobre a equação (7), é importante destacar que, conforme mencionado por Gerhards \& Mutz (2017), o sucesso nas ligas de futebol deve ser mensurado tendo em comparação os clubes da mesma competição. Logo, foi feita uma transformação $z$ das variáveis independentes para que as relações sejam consideradas levando em conta os clubes da mesma liga no mesmo ano, a fim de que possam ser comparados em ambos torneios analisados. Ao realizar a transformação z pôde-se notar que, por exemplo, no ano de 2013, Santos no Brasil e Vélez Sarsfield na Argentina tiveram valores de mercado médio de jogadores- $Z$ rigorosamente iguais a 1,32 . Isso significa que os dois clubes tinham elencos de 1,32 desvios padrão acima da média se comparados aos demais times da mesma liga em termos de valor de mercado no referido ano.

$\mathrm{Na}$ sequência, são apresentadas informações sobre as variáveis independentes utilizadas na equação (7), sendo que as quatro primeiras foram baseadas em Gerhards \& Mutz (2017). As demais foram inseridas com o intuito de captar particularidades dos campeonatos brasileiro e argentino que pudessem influenciar no desempenho final das equipes nos respectivos campeonatos nacionais.

Iniciando pela média do valor de mercado de um elenco, essa é dada pela soma do valor de mercado dos jogadores do plantel, medido em euros, dividido pela quantidade de atletas que compuseram o mesmo em algum momento da liga nacional, cujas informações financeiras estão disponíveis no site Transfermarkt.com. De acordo com Gerhards \& Mutz (2017), o valor de mercado de um jogador, representado pela taxa de transferência que o clube paga ao adquirir seus direitos federativos, representa uma boa medida de habilidade do atleta. Mesmo que fique evidente apenas quando um jogador troca de clube, o VM dos atletas é constantemente estimado pelo Transfermarkt.com a partir do valor potencial do jogador obtido por meio de informações como tempo de contrato e valor da multa rescisória, desempenho esportivo, características e clube dos jogadores. Desta forma, é possível criar um VM potencial dos jogadores, mesmo quando eles permanecem no mesmo clube.

Importante destacar que os $V M$ disponibilizados pelo referido site são valores nominais medidos em euro. Sendo assim, para uma análise temporal da variável foi necessário transformar tais valores em valores reais, ou seja, corrigidos pela inflação, por meio do Índice de Preços ao Consumidor Harmonizado (HICP), calculado para os países membros da União Europeia. Esse índice é disponibilizado por EUROSTAT (2019) e reconhecido como variávelchave para a análise, pelo Banco Central Europeu, da inflação nos países membros.

Com o intuito de medir a desproporção do valor de mercado entre os atletas de um mesmo elenco, foi usada a variável CVE, que vem a ser o coeficiente de variação do valor de mercado do elenco. Como já exposto acima, o VM representa, em valores monetários, uma proxy para a qualidade técnica do jogador. Portanto, o objetivo da inclusão do CVE é verificar se a existência de poucos jogadores de alto nível técnico no elenco teria impacto relevante no sucesso da equipe. O coeficiente de variação do valor de mercado do elenco é dado pelo quociente, para cada clube, entre o desvio padrão do valor de mercado de seus jogadores e a média de tal valor.

A variável FLUT pretende capturar se a rotatividade existente dentro do elenco, ou seja, a saída e a entrada de jogadores, interfere no sucesso do time na liga. Gerhards \& Mutz (2017) usam, para mensurar tal variável, a soma dos atletas recém contratados com os que deixaram o time na janela anterior 
ao início do campeonato. Para o caso brasileiro, esse trabalho usa para a rotatividade do elenco a quantidade de transferências realizadas antes do início do campeonato nacional e no decorrer da competição ${ }^{3}$. Já no caso argentino, até 2014, são consideradas apenas as transferências feitas antes do início do Apertura, ou seja, apenas as transferências da janela do verão europeu (meio do ano); para 2015 consideraram-se as transferências das duas janelas de transações; para 2016 levou-se em conta somente as da janela de inverno (início do ano); e para 2016/2017 os dois períodos de transferência.

Passando para a variável TEC, a mesma indica o número de treinadores de uma mesma equipe ao longo do mesmo campeonato. O objetivo é mensurar o impacto da troca de comando técnico no desempenho final da equipe na liga.

A composição da idade dos atletas do elenco também é tida neste trabalho como um fator que pode influenciar o desempenho dos times na liga. Dessa forma, a variável $C V I$ busca captar se existe uma relação entre a desproporção da idade dos jogadores dentro do elenco e o sucesso no campeonato nacional. A obtenção da variável $C V I$ é análoga à do $C V E$, sendo dada pelo quociente, para cada clube, entre o desvio padrão da idade dos jogadores e a média de idade do elenco.

Para observar o impacto da participação em outras competições paralelas à disputa dos campeonatos nacionais, foi utilizada a variável QJO, que pretende verificar se a quantidade de jogos disputados em outros torneios vai interferir no sucesso do clube na primeira divisão da liga nacional. Para construir esta variável, foi considerado, para o Brasil, a soma do número de partidas realizadas na Taça Libertadores da América, Copa Sul-Americana e Copa do Brasil após o início do campeonato brasileiro e, para o campeonato argentino, são consideradas as duas competições continentais e a Copa da Argentina.

A Tabela 1 resume as variáveis utilizadas apresentando o nome, a descrição, a unidade de medida e a fonte das mesmas.

Sobre a variável dummy DCLUB, a mesma foi incorporada para captar os possíveis efeitos fixos referentes às características dos clubes participantes dos campeonatos brasileiro e argentino de futebol. A descrição detalhada de cada variável encontra-se na Tabela 2, sendo que as duas primeiras colunas são referentes ao Brasil e as duas últimas, à Argentina.

Para o caso brasileiro, considerou-se como base o Flamengo, por ser a equipe de maior torcida no país, e criaram-se dummies individuais para os 11 clubes com mais torcedores nos quatro estados de maior relevância em termos de conquistas e tradição no futebol: São Paulo, Rio de Janeiro, Minas Gerais e Rio Grande do Sul. Já as demais variáveis foram construídas considerando-se $o$ aspecto regional e as similaridades dos clubes envolvidos.

Já para o campeonato argentino, a equipe de maior torcida no país (Boca Juniors) também foi a base e definiu-se dummies individuais para os outros 4 clubes de maior torcida na Argentina e também para as equipes que foram campeãs no período. Já as variáveis restantes foram construídas com base na localização e similaridade dos clubes envolvidos.

Quanto à fonte de dados do estudo, as variáveis explicativas $V M, C V E$, ESTR e FLUT foram retiradas de Transfermarkt (2019). Esta é uma página da internet que contém informações sobre os valores de mercado dos atletas

\footnotetext{
${ }^{3}$ Como o campeonato brasileiro se inicia em período diferente dos principais campeonatos europeus, jogadores que se destacam no decorrer do referido campeonato acabam por sair no meio do mesmo para reforçarem os clubes europeus cujas competições começam apenas no meio do ano em questão.
} 
Tabela 1: Descrição da variável dependente e dos regressores da equação (7)

\begin{tabular}{|c|c|c|c|}
\hline Nome & Descrição & $\begin{array}{l}\text { Unidade } \\
\text { de medida }\end{array}$ & Fonte \\
\hline $\begin{array}{l}\text { Aproveitamento } \\
(\mathrm{APR})\end{array}$ & $\begin{array}{l}\text { Variável dependente que se refere } \\
\text { ao aproveitamento dos times ao fi- } \\
\text { nal do torneio em termos de pontos } \\
\text { conquistados }\end{array}$ & Porcentagem & oGol (2017) \\
\hline $\begin{array}{l}\text { Valor de } \\
\text { Mercado } \\
\text { (VM) }\end{array}$ & $\begin{array}{l}\text { Valor médio de mercado dos joga- } \\
\text { dores de uma equipe }\end{array}$ & $\begin{array}{l}\text { Valores reais } \\
\text { em Euros }(€) \text {, } \\
\text { corrigidos } \\
\text { pelo HICP }\end{array}$ & $\begin{array}{l}\text { Transfermarkt (2019) e } \\
\text { EUROSTAT (2019) }\end{array}$ \\
\hline $\begin{array}{l}\text { Coeficiente de } \\
\text { variação do } \\
\text { valor de mercado } \\
\text { do elenco }(\mathrm{CVE}) \\
\end{array}$ & $\begin{array}{l}\text { Quociente, para cada clube, entre o } \\
\text { desvio padrão do valor de mercado } \\
\text { de seus jogadores e a média de tal } \\
\text { valor }\end{array}$ & Porcentagem & Transfermarkt (2019) \\
\hline $\begin{array}{l}\text { Estrangeiro } \\
\text { (ESTR) }\end{array}$ & $\begin{array}{l}\text { Quantidade de jogadores não bra- } \\
\text { sileiros (campeonato brasileiro) e } \\
\text { não argentinos (campeonato argen- } \\
\text { tino) que compõe o elenco do time }\end{array}$ & Unidade & oGol (2017) \\
\hline $\begin{array}{l}\text { Flutuação } \\
\text { (FLUT) }\end{array}$ & $\begin{array}{l}\text { Soma da quantidade de jogadores } \\
\text { que entraram e saíram do elenco na } \\
\text { janela de transferências anterior ao } \\
\text { início do campeonato }\end{array}$ & Unidade & Transfermarkt (2019) \\
\hline $\begin{array}{l}\text { Técnicos } \\
\text { (TEC) }\end{array}$ & $\begin{array}{l}\text { Quantidade de treinadores que o } \\
\text { clube teve ao longo do campeonato }\end{array}$ & Unidade & $\begin{array}{c}\text { oGol (2017) } \\
\text { Footballdatabase (2017) }\end{array}$ \\
\hline $\begin{array}{l}\text { Coeficiente de } \\
\text { variação da } \\
\text { idade do } \\
\text { elenco }(\mathrm{CVI})\end{array}$ & $\begin{array}{l}\text { Quociente, para cada clube, entre o } \\
\text { desvio padrão da idade dos jogado- } \\
\text { res e a média de idade do elenco }\end{array}$ & Porcentagem & oGol (2017) \\
\hline $\begin{array}{l}\text { Quantidade } \\
\text { de jogos } \\
\text { simultâneos } \\
\text { à liga }(\mathrm{QJO}) \\
\end{array}$ & $\begin{array}{l}\text { Quantidade de jogos disputados } \\
\text { simultaneamente à liga, conside- } \\
\text { rando as copas nacionais e interna- } \\
\text { cionais }\end{array}$ & Unidade & oGol (2017) \\
\hline $\begin{array}{l}\text { Promoção } \\
\text { (PROM) }\end{array}$ & $\begin{array}{l}\text { Dummy que assume valor } 1 \\
\text { quando o clube veio da } 2^{\circ} \text { divisão } \\
\text { no ano anterior e } 0 \text {, caso contrário }\end{array}$ & $\begin{array}{c}\text { Variável } \\
\text { Qualitativa } \\
(1 \text { ou } 0)\end{array}$ & oGol (2017) \\
\hline $\begin{array}{l}\text { Efeito fixo } \\
\text { de clubes } \\
\text { (DCLUB) }\end{array}$ & $\begin{array}{l}\text { Dummy que assume valor } 1 \\
\text { quando representa o clube ou clu- } \\
\text { bes em questão e } 0 \text {, caso contrário }\end{array}$ & $\begin{array}{c}\text { Variável } \\
\text { Qualitativa } \\
(1 \text { ou } 0)\end{array}$ & oGol (2017) \\
\hline
\end{tabular}

Fonte: Elaboração própria

individualmente e dos elencos dos clubes para diversos anos. As informações referentes à variável dependente $A P R$, assim como dos regressores TEC, CVI, QJO, PROM e DCLUB foram retiradas dos sites oGol (2017) e Footballdatabase (2017), que são páginas da internet que contém informações e estatísticas variadas sobre diversos campeonatos e clubes ao redor do mundo.

\section{Resultados}

A análise dos resultados se divide em dois tópicos. No primeiro é feita uma análise descritiva das variáveis utilizadas nos modelos, sendo o principal foco descrever as diferenças verificadas entre os campeonatos brasileiro e argentino de futebol. No segundo tópico são apresentados e discutidos os resultados da análise econométrica dos modelos regredidos.

\subsection{Análise descritiva das variáveis utilizadas para os campeonatos brasileiro e argentino de futebol da primeira divisão no período 2006-2017}

Iniciando pela variável dependente que mede o aproveitamento final em termos de porcentagem dos pontos conquistados por cada equipe ao longo do 
Tabela 2: Descrição das variáveis dummies referentes aos efeitos fixos dos clubes

\begin{tabular}{|c|c|c|c|}
\hline Nome & Clube (s) & Nome & Clube (s) \\
\hline DSP & São Paulo & DRIV & River Plate \\
\hline DCOR & Corinthians & DEST & Estudiantes \\
\hline$\overline{\text { DSAN }}$ & Santos & DSL & San Lorenzo \\
\hline DPAL & Palmeiras & DVEL & Vélez Sarsfield \\
\hline DVAS & Vasco & DIND & Independiente \\
\hline DFLU & Fluminense & DRAC & Racing \\
\hline DBOT & Botafogo & - & - \\
\hline$\overline{\mathrm{DCRU}}$ & Cruzeiro & - & - \\
\hline DCAM & Atlético-MG & - & - \\
\hline DGRE & Grêmio & - & - \\
\hline DINT & Internacional & - & - \\
\hline $\begin{array}{l}\text { DNE } \\
\text { (Nordeste) }\end{array}$ & $\begin{array}{l}\text { América-RN, Ceará, } \\
\text { Fortaleza, Bahia, Vi- } \\
\text { tória, Sport, Náutico } \\
\text { e Santa Cruz }\end{array}$ & DLB & Lanús e Banfield \\
\hline $\begin{array}{l}\text { DCUR } \\
\text { (Curitiba) }\end{array}$ & $\begin{array}{l}\text { Atlético-PR e Cori- } \\
\text { tiba }\end{array}$ & DROS & $\begin{array}{lll}\text { Rosario Central } & \text { e } \\
\text { Newell's Old Boys } & \\
\end{array}$ \\
\hline $\begin{array}{l}\text { DSUL } \\
\text { (Sul) }\end{array}$ & $\begin{array}{l}\text { Avaí, Criciúma, Cha- } \\
\text { pecoense, Joinville, } \\
\text { Figueirense, Paraná } \\
\text { Clube e Juventude }\end{array}$ & $\begin{array}{l}\text { DBA (Província } \\
\text { de Buenos Ai- } \\
\text { res) }\end{array}$ & $\begin{array}{l}\text { Argentinos Jrs, Arsenal, } \\
\text { Aldosivi, Huracán, Ti- } \\
\text { gre, Olimpo, Gimnasia } \\
\text { La Plata, Defensa y Jus- } \\
\text { ticia, Quilmes, Sarmi- } \\
\text { ento, Temperley, Nu- } \\
\text { eva Chicago, All Boys e } \\
\text { Chacarita Jrs }\end{array}$ \\
\hline $\begin{array}{l}\text { DCO } \\
\text { (Centro- } \\
\text { Oeste) }\end{array}$ & Goiás e Atlético-GO & $\begin{array}{l}\text { DFBA (Fora da } \\
\text { Província de Bu- } \\
\text { enos Aires) }\end{array}$ & $\begin{array}{l}\text { Colón, Unión Santa } \\
\text { Fé, Talleres, Belgrano, } \\
\text { San Martin SJ, Godoy } \\
\text { Cruz, Tucumán, San } \\
\text { Martin Tucumán, Pa- } \\
\text { tronato, Crucero del } \\
\text { Norte, Atlético Rafaela } \\
\text { e Gimnasia Jujuy }\end{array}$ \\
\hline $\begin{array}{l}\text { DOUT } \\
\text { (Outros) }\end{array}$ & $\begin{array}{l}\text { Ponte Preta, Guarani, } \\
\text { Santo André, Grêmio } \\
\text { Barueri (Prudente), } \\
\text { São Caetano, Portu- } \\
\text { guesa, América-MG } \\
\text { e Ipatinga }\end{array}$ & - & ( \\
\hline
\end{tabular}


campeonato disputado, tem-se a Tabela 3.

Observa-se que no período 2006-2017, o aproveitamento médio do campeão brasileiro foi de $65,75 \%$, enquanto na Argentina, tal resultado foi de $71,17 \%$. O clube que conquistou o título brasileiro com maior aproveitamento foi o Corinthians em 2015 (71\%), enquanto que o campeão com pior desempenho foi o Flamengo em 2009 (58\%). Para o campeonato argentino, o melhor e o pior aproveitamento dos vencedores foram, respectivamente, do Lanús em 2016 (79\%) e do San Lorenzo em 2013 (57\%).

Através da apresentação dos gráficos referentes à média anual de cada uma das variáveis explicativas relativas às ligas dos dois países, é possível fazer uma análise sobre as tendências e diferenças entre os campeonatos em relação aos fatores elucidados neste estudo, comparando as características de cada torneio em um horizonte temporal.

A Figura 1 mostra o comportamento do valor de mercado médio dos jogadores dos elencos $(V M)$, medido em euros reais com correção da inflação pelo HICP, para cada edição das competições brasileira e argentina. Ao observá-la, é possível notar que, até o ano de 2009, os campeonatos tinham valores de mercado de jogadores médios aproximados e, a partir desse ano, a distância desta variável entre os dois países passou a aumentar cada vez mais. Um dos possíveis motivos para tal distanciamento foi a implementação em 2009 do programa Fútbol Para Todos (FPT), que consistiu na compra dos direitos de transmissão do campeonato argentino pelo governo da então presidente, Cristina Kirchner. Se por um lado tal política ajudou aos clubes que se encontravam no momento em grave crise financeira, diminuiu ainda mais a capacidade de investimento das equipes maiores, uma vez que os direitos de transmissão passaram a ser divididos entre os participantes da competição de forma igualitária (Mena 2009). Com o fim do programa a partir de 2017, A Federação Argentina de Futebol (AFA), detentora dos direitos de transmissão do campeonato argentino, negociou um novo acordo de venda do campeonato, cujo valor era quase o dobro do que era recebido por meio do programa estatal. A partir de então, observa-se o aumento no $V M$ do campeonato argentino, beneficiando principalmente aos grandes clubes que passaram a receber maiores valores referentes à transmissão dos jogos, notadamente, Boca Juniors e River Plate (Giovanaz 2017).

Apesar disso, percebe-se que as cotas de transmissão pagas aos clubes no Brasil ainda são bem superiores em comparação ao praticado na Argentina, visto que em 2017, o valor desembolsado pelos direitos de transmissão do campeonato brasileiro (cerca de $\mathrm{R} \$ 1,8$ bilhão) foi mais do que o dobro em comparação ao repassado pelo campeonato argentino (R\$650 milhões) (Bonsanti 2017).

Dessa forma, de modo geral, ao comparar as médias, fica visível o maior poder de mercado do futebol brasileiro, visto que apenas em 2007 o campeonato argentino teve $V M$ médio maior que o do brasileiro. Portanto, considerando o VM como um indicativo de qualidade dos atletas, pode-se afirmar que o campeonato brasileiro da primeira divisão tem qualidade técnica superior à primeira divisão argentina.

Na sequência, a Figura 2 expõe a disparidade média do $V M$, ou seja, o CVE dentro dos elencos das ligas.

Em relação ao $C V E$, observa-se que o valor de tal variável foi maior para o Brasil em praticamente todo o período, embora a partir de 2014 os valores tenham ficado próximos para os dois países. Isto mostra que há uma tendência 
Tabela 3: Aproveitamento dos campeões e dos clubes que disputaram todas as edições dos campeonatos brasileiro e argentino de futebol da primeira divisão no período 2006-2017

\begin{tabular}{l|c|c|c|c|c|c|c|c|c|c|c|c}
\hline & \multicolumn{10}{c}{ ANO } \\
\hline CLUBE & 2006 & 2007 & 2008 & 2009 & 2010 & 2011 & 2012 & 2013 & 2014 & 2015 & 2016 & 2017 \\
\hline Campeão-BRA & $\mathbf{0 , 6 8}$ & $\mathbf{0 , 6 7}$ & $\mathbf{0 , 6 5}$ & $\mathbf{0 , 5 8}$ & $\mathbf{0 , 6 2}$ & $\mathbf{0 , 6 2}$ & $\mathbf{0 , 6 7}$ & $\mathbf{0 , 6 6}$ & $\mathbf{0 , 7 0}$ & $\mathbf{0 , 7 1}$ & $\mathbf{0 , 7 0}$ & $\mathbf{0 , 6 3}$ \\
\hline Cruzeiro & 0,38 & 0,52 & 0,58 & 0,54 & 0,60 & 0,37 & 0,45 & $\mathbf{0 , 6 6}$ & $\mathbf{0 , 7 0}$ & 0,48 & 0,44 & 0,50 \\
Flamengo & 0,42 & 0,53 & 0,56 & $\mathbf{0 , 5 8}$ & 0,38 & 0,53 & 0,43 & 0,39 & 0,45 & 0,42 & 0,62 & 0,49 \\
Fluminense & 0,50 & 0,53 & 0,39 & 0,40 & $\mathbf{0 , 6 2}$ & 0,55 & $\mathbf{0 , 6 7}$ & 0,40 & 0,53 & 0,41 & 0,43 & 0,41 \\
Santos & 0,45 & 0,54 & 0,39 & 0,42 & 0,49 & 0,46 & 0,46 & 0,50 & 0,46 & 0,50 & 0,62 & 0,55 \\
São Paulo & $\mathbf{0 , 6 8}$ & $\mathbf{0 , 6 7}$ & $\mathbf{0 , 6 5}$ & 0,57 & 0,48 & 0,51 & 0,57 & 0,43 & 0,61 & 0,54 & 0,45 & 0,43 \\
\hline Campeão-ARG & $\mathbf{0 , 7 7}$ & $\mathbf{0 , 6 6}$ & $\mathbf{0 , 6 8}$ & $\mathbf{0 , 7 1}$ & $\mathbf{0 , 7 8}$ & $\mathbf{0 , 7 5}$ & $\mathbf{0 , 7 1}$ & $\mathbf{0 , 5 7}$ & $\mathbf{0 , 7 1}$ & $\mathbf{0 , 7 1}$ & $\mathbf{0 , 7 9}$ & $\mathbf{0 , 7 0}$ \\
\hline Arsenal & 0,56 & 0,43 & 0,49 & 0,47 & 0,56 & 0,42 & 0,54 & 0,52 & 0,45 & 0,30 & 0,56 & 0,30 \\
Boca Juniors & 0,77 & 0,54 & 0,68 & 0,47 & 0,43 & $\mathbf{0 , 7 5}$ & 0,57 & 0,50 & 0,54 & 0,71 & 0,41 & $\mathbf{0 , 7 0}$ \\
Estudiantes & $\mathbf{0 , 7 7}$ & 0,54 & 0,49 & 0,54 & $\mathbf{0 , 7 8}$ & 0,40 & 0,49 & 0,47 & 0,54 & 0,56 & 0,66 & 0,62 \\
Lanús & 0,54 & $\mathbf{0 , 6 6}$ & 0,64 & 0,54 & 0,49 & 0,50 & 0,59 & 0,54 & 0,61 & 0,46 & $\mathbf{0 , 7 9}$ & 0,55 \\
Independiente(1) & 0,56 & 0,49 & 0,31 & 0,59 & 0,24 & 0,47 & 0,29 & - & 0,57 & 0,60 & 0,56 & 0,58 \\
Newell's & 0,28 & 0,43 & 0,54 & 0,68 & 0,45 & 0,28 & 0,63 & 0,54 & 0,43 & 0,44 & 0,33 & 0,54 \\
Racing & 0,45 & 0,43 & 0,38 & 0,29 & 0,50 & 0,54 & 0,57 & 0,54 & $\mathbf{0 , 7 1}$ & 0,63 & 0,50 & 0,61 \\
River Plate(1) & 0,66 & 0,40 & 0,24 & 0,36 & 0,54 & - & 0,50 & 0,36 & 0,68 & 0,54 & 0,37 & 0,62 \\
San Lorenzo & 0,49 & 0,50 & $\mathbf{0 , 6 8}$ & 0,56 & 0,42 & 0,33 & 0,45 & $\mathbf{0 , 5 7}$ & 0,45 & 0,67 & 0,70 & 0,58 \\
Vélez Sarsfield & 0,52 & 0,47 & 0,45 & 0,59 & 0,75 & 0,54 & $\mathbf{0 , 7 1}$ & 0,54 & 0,43 & 0,32 & 0,50 & 0,41 \\
\hline Fonte: Elaboraç
\end{tabular}

Fonte: Elaboração própria.

Nota: (1) Embora Independiente e River Plate não tenham disputado as edições dos campeonatos argentinos da primeira

divisão nos anos de 2013 e 2011, respectivamente, eles foram mantidos na Tabela 3 pelo fato de serem, ao lado de Boca Juniors,

Racing e San Lorenzo, os cinco grandes clubes do país. 
Figura 1: Valor real de mercado médio dos jogadores, em euros, dos elencos dos times dos campeonatos brasileiro e argentino de futebol, 20062017.

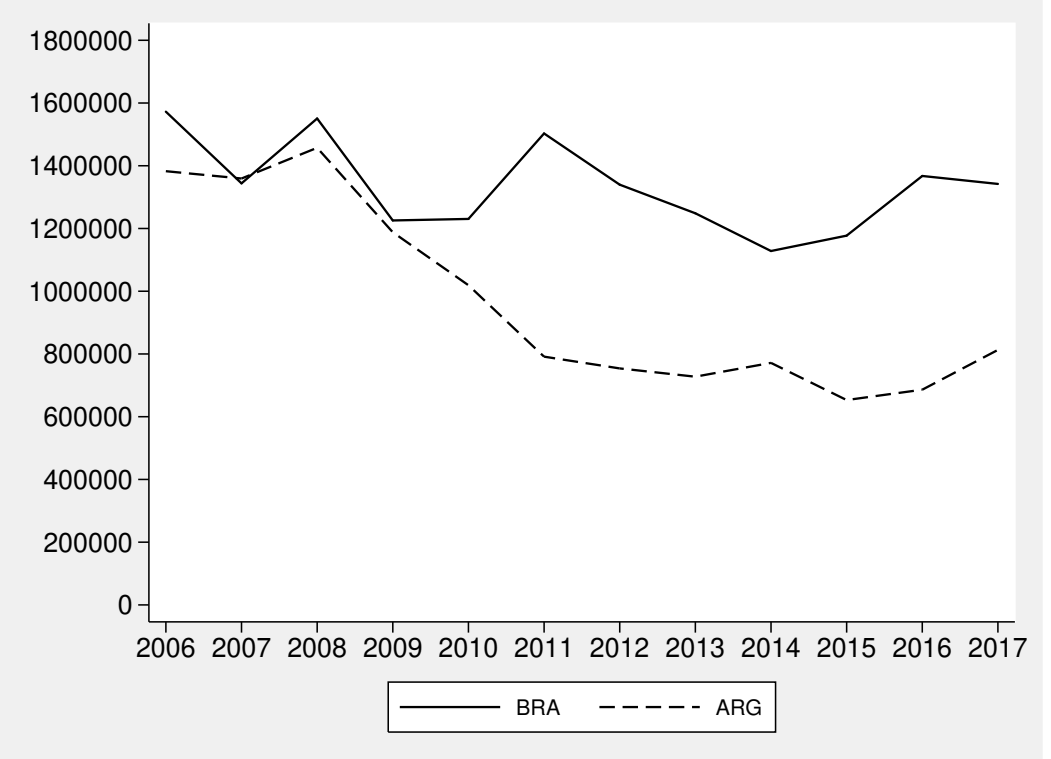

Fonte: Elaboração própria.

Figura 2: Média do coeficiente de variação do VM dos elencos dos times dos campeonatos brasileiro e argentino de futebol, 2006-2017.

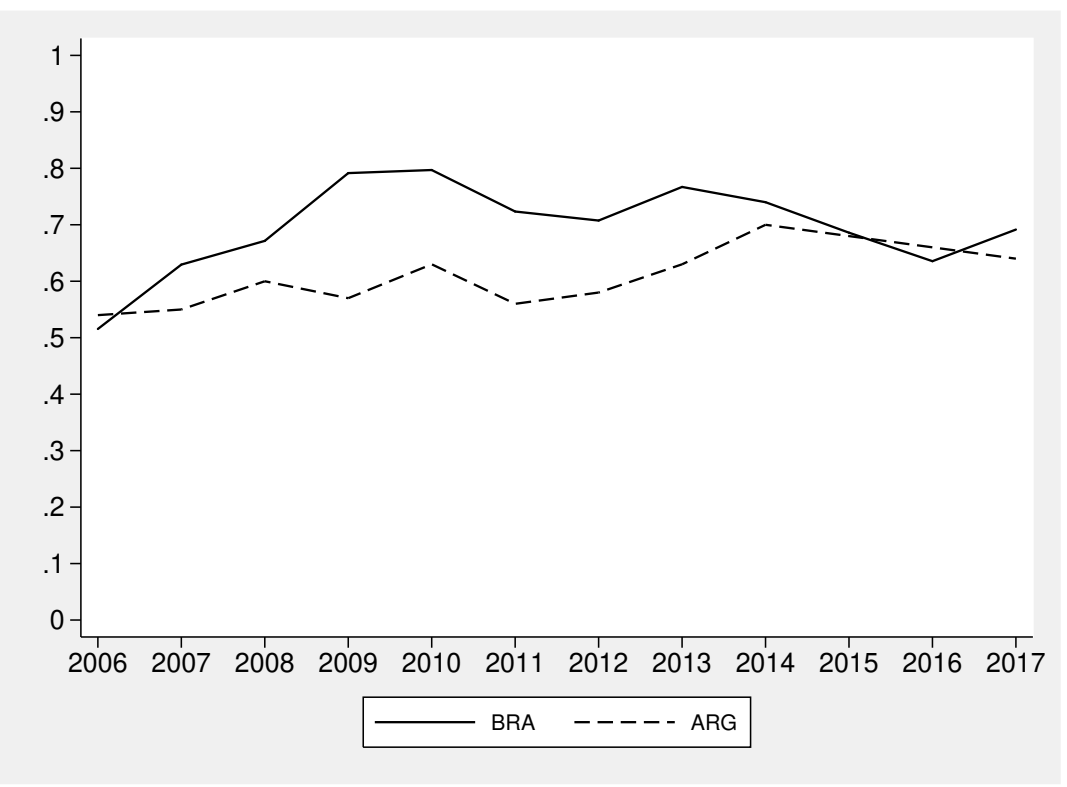

Fonte: Elaboração própria. 
entre os times da primeira divisão, tanto do Brasil quanto da Argentina, em padronizar a composição financeira do elenco, ou seja, buscar jogadores com $V M$ parecidos de forma a homogeneizar a qualidade do elenco, diminuindo a dependência por alguns atletas e fortalecendo a coesão do grupo através de jogadores de nível técnico próximo.

A seguir, a Figura 3 mostra a média de estrangeiros anual encontrada na amostra das duas ligas sul-americanas em análise.

Figura 3: Média de estrangeiros nos elencos dos times dos campeonatos brasileiro e argentino de futebol, 2006-2017.

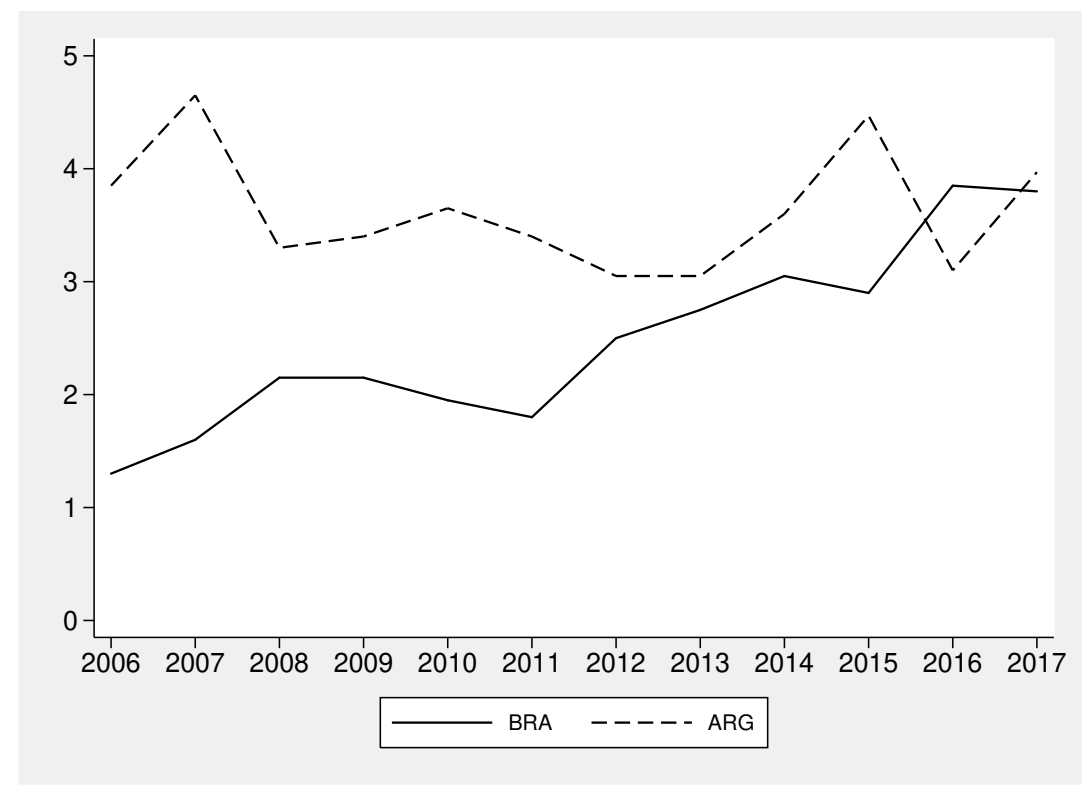

Fonte: Elaboração própria.

Destaca-se no período, o aumento de número de estrangeiros dentro do campeonato brasileiro, chegando inclusive a praticamente igualar-se ao verificado no campeonato argentino em 2017. Tal fato foi o resultado conjunto dos seguintes fatores: aumento do limite do número de estrangeiros por partida de 3 para 5 a partir da temporada de 2014 pela Confederação Brasileira de Futebol (CBF), mudança de perfil das diretorias dos clubes brasileiros que passaram a monitorar oportunidades de negócio em todo o continente sulamericano e maior poder aquisitivo das equipes do Brasil em comparação aos demais países da América do Sul (Gammaro 2017).

A Figura 4 apresenta as médias das flutuações dos elencos nos campeonatos brasileiro e argentino. Verifica-se que, na primeira competição, a rotatividade dos elencos é maior, indicando que, no Brasil, a troca de jogadores no plantel é feita com mais intensidade em comparação ao praticado na Argentina.

Em seguida, a Figura 5 mostra a média de treinadores das equipes nas ligas de futebol de Brasil e Argentina de acordo com a amostra da pesquisa. Os resultados mostraram que a média de treinadores no campeonato brasileiro foi superior em todos os anos da amostra se comparado ao torneio argentino, exceto em 2017, onde as médias se igualaram. Tal fato vai ao encontro do 
Figura 4: Média de flutuação dos elencos dos times dos campeonatos brasileiro e argentino de futebol, 2006-2017.

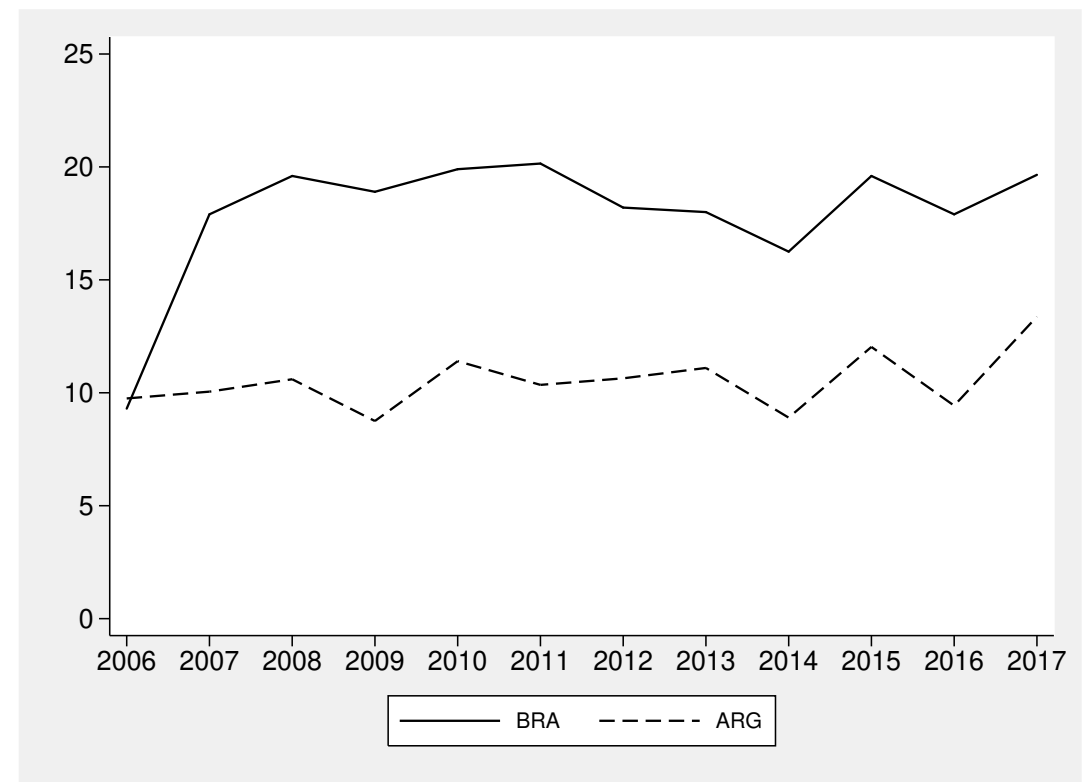

Fonte: Elaboração própria.

relatório divulgado em 2016 pela CIES Football Observatory, o qual aponta que das 5 grandes ligas da Europa, inglesa, alemã, francesa, espanhola e italiana, esta última é a que possui o menor tempo médio de um técnico no cargo de um time, sendo este de 9 meses. No campeonato brasileiro, este período é de 5,7 meses (Gonçalves 2016). Além disso, o tempo médio de permanência no cargo de um técnico no Brasil é menor se comparado à Argentina. No futebol argentino, a média de um treinador no comando do clube é de 34 jogos, contra 15 no futebol brasileiro (Guma 2015).

A Figura 6 exibe a média do coeficiente de variação de idade amostral para as ligas nacionais brasileira e argentina. De todas as variáveis utilizadas neste trabalho, a que mais se aproximou entre os países ao longo do período foi o $C V I$, indicando que de forma geral, os elencos das equipes nas duas competições apresentaram padrão de idade parecidos ao longo do período analisado.

Adiante, segue a Figura 7 que expõe a média de jogos simultâneos que aconteceram em relação aos campeonatos locais brasileiro e argentino. Observase que, ao longo de todo o período, as equipes brasileiras jogaram, em média, mais partidas do que as argentinas, confirmando que o Brasil é um dos países onde os clubes mais disputam partidas, conforme apontado por estudo de Footstats (2017). Nesse último, utilizando dados da temporada de 2017, verificou-se que, no Brasil, joga-se, em média, 56\% a mais do que nas principais ligas do mundo. $\mathrm{O}$ mesmo trabalho aponta que, enquanto no referido país os clubes jogam, em média, 68,7 jogos por temporada, na Argentina esse valor é de 35,8 partidas, ou seja, quase a metade.

Ainda sobre a Figura 7, destaca-se também que em ambas as ligas há tendência de elevação do número de jogos simultâneos, já que aumentou o número de vagas para os países na Copa Libertadores e, além disso, os clubes que disputam até o final a principal competição da América do Sul não po- 
Figura 5: Média de treinadores dos times dos campeonatos brasileiro e argentino de futebol, 2006-2017.

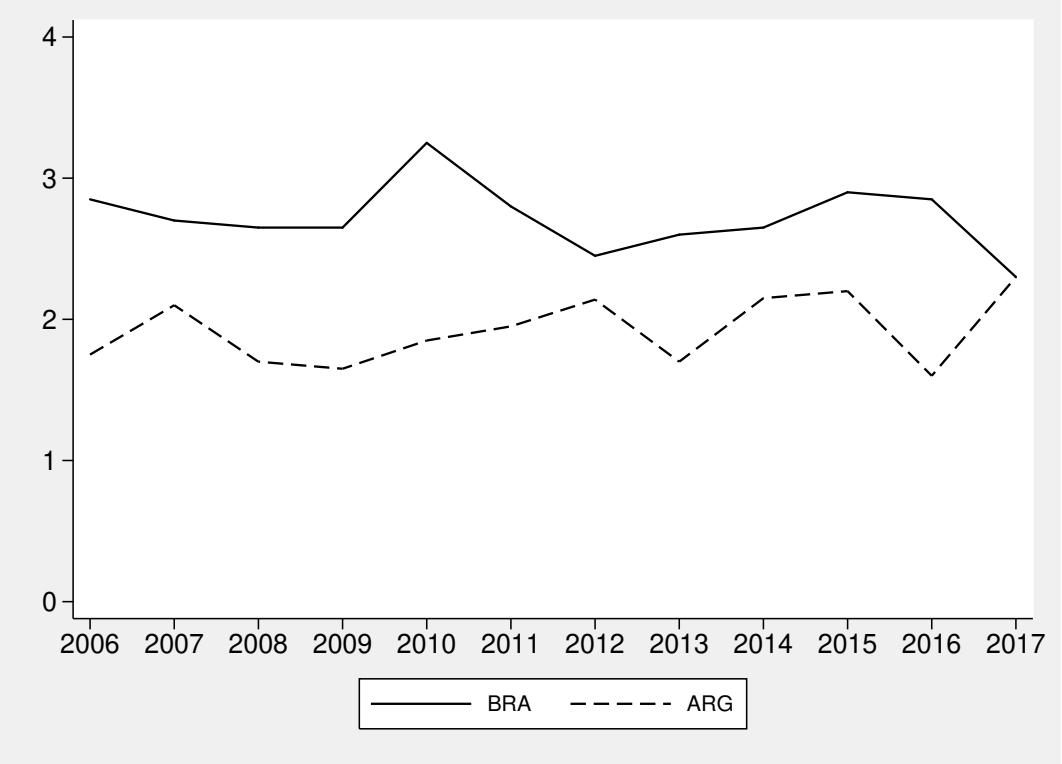

Fonte: Elaboração própria.

Figura 6: Média do coeficiente de variação da idade dos elencos dos times dos campeonatos brasileiro e argentino de futebol, 2006-2017.

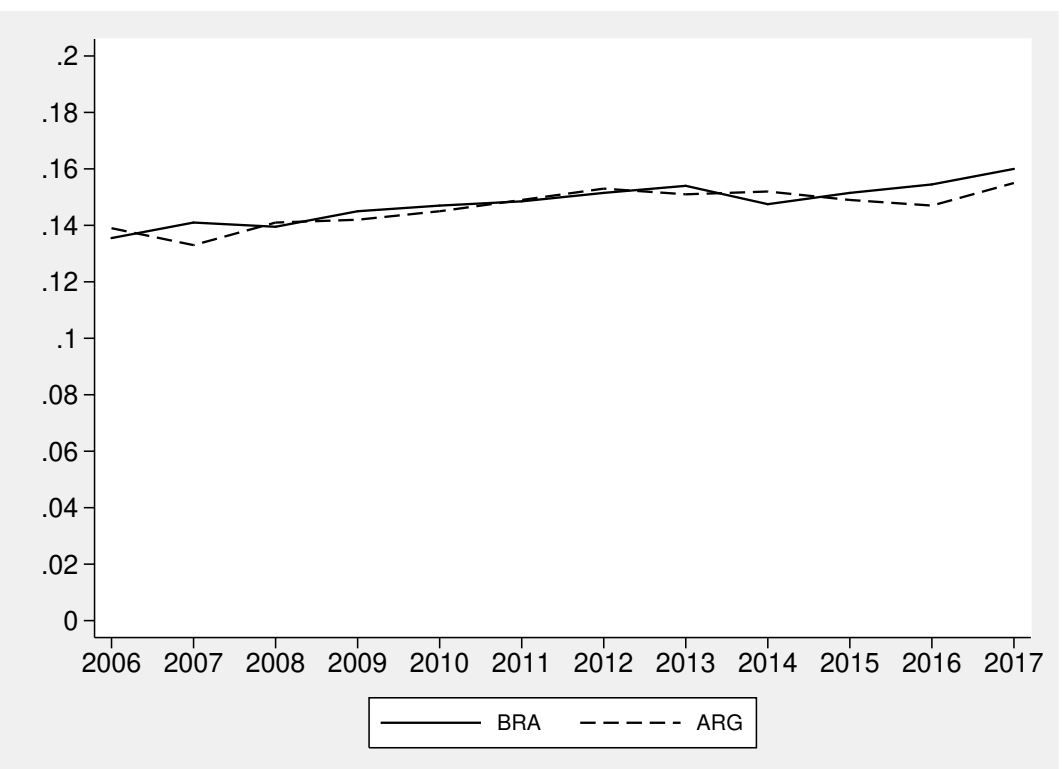

Fonte: Elaboração própria. 
dem mais jogar a Sul-Americana. Estas situações devem elevar a média deste fator nas próximas temporadas, já que mais clubes destas ligas tendem a jogar estas competições internacionais.

Destaca-se ainda que, para a Argentina, observou-se que em 2012, a quantidade média de jogos aumentou de patamar em virtude da volta da competição Copa da Argentina.

Figura 7: Média de quantidade de jogos simultâneos dos times dos campeonatos brasileiro e argentino de futebol, 2006-2017.

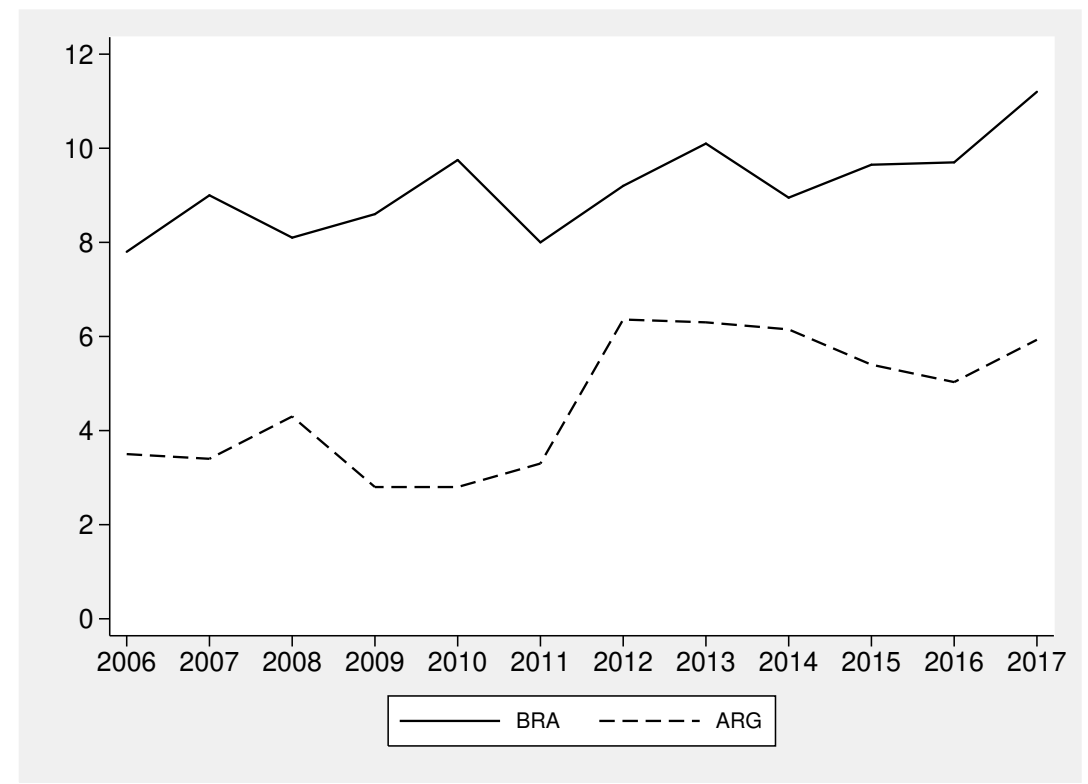

Fonte: Elaboração própria.

Por fim, apresenta-se na Figura 8, a quantidade de recém-promovidos tanto na liga brasileira quanto na argentina. No campeonato brasileiro, notase o mesmo número de promovidos a partir de 2007.

Isso é explicado pelo fato de que em 2006 foi o ano em que a liga nacional passou a contar com 20 clubes e, para que isto ocorresse, em 2005 caíram 4 equipes e subiram somente 2. Desde então, todo ano no Brasil, caem 4 times e sobem a mesma quantidade, mantendo, portanto, a quantidade constante.

Por outro lado, na Argentina o sistema de acesso e descenso passou por diversas alterações no período em questão. De 2006 a 2014, o rebaixamento era baseado no Promedios, que levava em conta o desempenho das equipes nas últimas três temporadas, incluindo os torneios Apertura e Clausura. Dessa forma, os dois piores colocados no Promedios entre os 20 times ao final do Clausura eram rebaixados diretamente para a segunda divisão, enquanto que o $17^{\circ}$ e $18^{\circ}$ desse ranqueamento disputavam um play-off contra o terceiro e quarto colocados da segunda divisão, sendo que o campeão e vice desse último campeonato ascendiam diretamente para a disputa do Apertura no ano em questão. Portanto, a existência de play-offs nesse período alterou constantemente o número de equipes que subiram ou caíram de divisão ao final de cada temporada. Em 2015, o campeonato teve 10 equipes promovidas, isto por que, neste ano especificamente, a liga argentina unificou os dois torneios 
em um único campeonato e passou a ter 30 clubes na primeira divisão. Em 2016, os dois últimos do Promedios foram rebaixados, enquanto que o campeão e o vice da segunda divisão subiram para a primeira divisão. Por fim, para o campeonato considerado em 2017, apenas o último colocado da competição anterior foi rebaixado, enquanto que somente o campeão da segunda divisão subiu para a primeira divisão.

Figura 8: Quantidade de clube recém-promovidos da segunda divisão nos campeonatos brasileiro e argentino de futebol, 2006-2017.

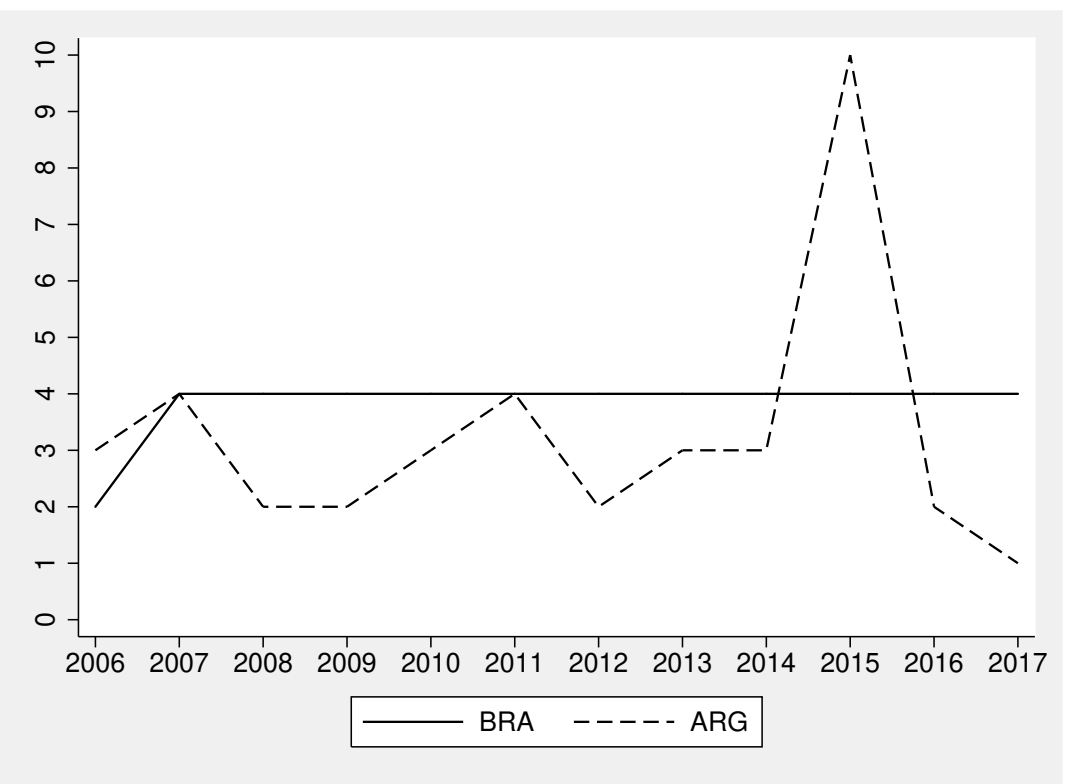

Fonte: Elaboração própria.

Perante a análise descritiva no período 2006-2017, pôde-se notar que o futebol brasileiro em comparação ao argentino, apresentou maiores valor de mercado médio dos jogadores, flutuação nos elencos, número de treinadores por equipe durante o campeonato e números de jogos ao longo da temporada. Em termos específicos, destacou-se no Brasil, o aumento do número de estrangeiros nos clubes. Já para a Argentina, ressaltaram-se as constantes mudanças de formato e número de equipes participantes na competição a partir de 2014 .

\subsection{Determinantes do aproveitamento percentual, em termos do total de pontos obtidos, nos campeonatos brasileiro e argentino de futebol da primeira divisão no período 2006-2017}

Nesta seção são apresentados e discutidos os resultados das regressões beta para os campeonatos brasileiro e argentino de futebol conforme equação (7). Destaca-se que como apontado na metodologia, tal regressão é adequada para a estimativa de variável dependente percentual desde que os valores da mesma estejam no intervalo $0<y<1$. Esse é o caso do presente estudo, já que o menor valor de $y$ para Brasil e Argentina são, respectivamente, 0,1491 (América de Natal em 2007) e 0,1053 (Cólon em 2013). Já os maiores valores de $y$ são 0,7105 (Corinthians no Brasil em 2015) e 0,7917 (Lanús na Argentina em 2016). 
Assim, a Tabela 4 apresenta os resultados das estimações para os modelos com menor BIC para o Brasil e para a Argentina, considerando todas as combinações possíveis entre as funções de ligação e as funções de ligação de escala apresentadas na metodologia. Importante observar que para os dois campeonatos, os valores BIC para os modelos foram bastante próximos, variando de $-336,98$ a $-337,75$ para a Argentina, e de $-458,02$ a $-458,47$ para o Brasil, indicando pouca sensibilidade dos resultados a alterações na função de ligação ou na função de ligação de escala.

Para o campeonato brasileiro, a função de ligação mais adequada foi a loglog, sendo que o ajuste em termos de função de ligação de escala foi o mesmo para as três possibilidades disponíveis. O mesmo aconteceu para o campeonato argentino em termos de função de ligação de escala, embora para este país, a melhor função de ligação tenha sido a cloglog.

De acordo com os valores encontrados na pesquisa, o valor médio de mercado real dos jogadores $V M$ e o número de treinadores por equipe ao longo do campeonato (Treinador) foram significativos para os dois países, embora as forma quadrática da primeira variável tenha sido apenas para o Brasil, enquanto que a quantidade de jogos em outras competições simultâneos aos campeonatos brasileiro e argentino (QJogos) e sua forma quadrática foram significativos somente para a Argentina. Para os dois campeonatos, ocorreram variáveis dummies de clubes significativas, indicando a importância de se considerar os possíveis impactos de efeitos fixos das equipes no aproveitamento das mesmas. Em termos de significância global, o teste Wald qui-quadrado foi significativo a $1 \%$ para os dois países, mostrando que, conjuntamente, as variáveis são adequadas para a análise. Posto isto, são expostas as interpretações das variáveis, comparando o comportamento das mesmas entre as duas ligas nacionais.

Importante destacar que, na regressão beta, os coeficientes estimados apenas indicam se o impacto dos regressores sobre o regressando é positivo ou negativo. Dessa forma, para obtenção do efeito marginal dos primeiros sobre o segundo, utilizou-se o comando margins do software Stata.

O VM tem impacto positivo no aproveitamento em pontos ao final da liga tanto no campeonato brasileiro quanto no argentino, sendo que, para o caso brasileiro, ao aumentar o VM médio do jogador em um desvio padrão, mantendo as demais variáveis constantes, o aproveitamento aumenta em 2,5 pontos percentuais (pp), sendo esse valor para a Argentina é de 2,2 pp. Considerando que a média total do VM por jogador para o período de 2006 a 2017 para o Brasil e a Argentina é de, respectivamente, $€ 1.335 .737$ e $€ 966.301 \mathrm{e}$ um desvio padrão corresponde a $€ 111.459$ para o Brasil e $€ 261.966$ para a Argentina, então, na liga brasileira, o VM médio por atleta deveria ser acrescido em $€ 111.459$, e na liga argentina, este valor seria de $€ 261.966$ para alcançar os respectivos aumentos de aproveitamento em cada uma das ligas. Considerando um elenco com 24 jogadores, o investimento adicional para elevar os respectivos desempenhos em pp teriam que ser de $€ 2.675 .016$ no Brasil e $€$ 6.287.184 na Argentina.

Dessa forma, observa-se que o impacto do $V M$ mostrou-se importante e muito próximo para as ligas dos dois países. Além disso, como o valor médio de mercado dos jogadores do campeonato brasileiro é $38,23 \%$ superior ao do argentino, têm-se que a liga brasileira é melhor em termos de qualidade técnica dos jogadores. Essa pode ser uma possível explicação para o fato de a forma quadrática do $V M$ ter sido significativa apenas para o Brasil. Isso 
Tabela 4: Determinantes do desempenho, em termos de aproveitamento percentual dos pontos conquistados, ao final dos campeonatos brasileiro e argentino de futebol, $2006-2017$

\begin{tabular}{|c|c|c|}
\hline Aproveitamento & Brasil & Argentina \\
\hline VM & $\begin{array}{l}0,070^{* * *} \\
(0,021)\end{array}$ & $\begin{array}{l}0,068^{* *} \\
(0,033)\end{array}$ \\
\hline $\mathrm{VM}^{2}$ & $\begin{array}{c}-0,024^{* *} \\
(0,010)\end{array}$ & $\begin{array}{r}-0,005 \\
(0,010)\end{array}$ \\
\hline CVE & $\begin{array}{l}0,0004 \\
(0,012)\end{array}$ & $\begin{array}{r}-0,017 \\
(0,020)\end{array}$ \\
\hline Estrangeiro & $\begin{array}{r}-0,016 \\
(0,014)\end{array}$ & $\begin{array}{r}-0,030 \\
(0,019)\end{array}$ \\
\hline Flutuação & $\begin{array}{l}0,004 \\
(0,012)\end{array}$ & $\begin{array}{r}-0,028 \\
(0,019)\end{array}$ \\
\hline CVI & $\begin{array}{l}0,007 \\
(0,012)\end{array}$ & $\begin{array}{r}-0,028 \\
(0,017)\end{array}$ \\
\hline Treinador & $-0,106^{* * *}$ & $-0,134^{* * *}$ \\
\hline Treinador $^{2}$ & $\begin{array}{l}0,008 \\
(0,005)\end{array}$ & $\begin{array}{l}0,010 \\
(0,012)\end{array}$ \\
\hline Qjogos & $\begin{array}{l}0,001 \\
(0,012)\end{array}$ & $\begin{array}{l}0,080^{* * *} \\
(0,029)\end{array}$ \\
\hline Qjogos $^{2}$ & $\begin{array}{c}-0,0002 \\
(0,008)\end{array}$ & $-{ }^{0,033^{* * *}}$ \\
\hline Série B & $\begin{array}{l}0,005 \\
(0,040)\end{array}$ & $\begin{array}{r}-0,040 \\
(0,057)\end{array}$ \\
\hline DNE / DBA & $-{ }^{0,148^{* *}}$ & $-{ }^{0,306^{* *}}$ \\
\hline DSUL / DFBA & $\begin{array}{c}-0,138^{* *} \\
(0,070)\end{array}$ & $\begin{array}{c}-0,286^{* *} \\
(0,130)\end{array}$ \\
\hline DOUT & $\begin{array}{c}-0,249^{* * *} \\
(0,072)\end{array}$ & - \\
\hline Intercepto & $\begin{array}{l}0,275^{* * *} \\
(0,023)\end{array}$ & $\begin{array}{l}0,120^{* * *} \\
(0,044)\end{array}$ \\
\hline Observações & 240 & 270 \\
\hline Wald qui-quadrado & $339,99^{* * *}$ & $210,62^{* * *}$ \\
\hline \multicolumn{3}{|c|}{$\begin{array}{l}\text { Fonte: Elaboração própria. } \\
\text { Notas: } \\
\text { *** significativo a } 1 \%{ }^{* *} \text { significativo a } 5 \% \text {. } \\
\text { Na Tabela } 4 \text { foram apresentados apenas os resultados das } \\
\text { dummies dos efeitos fixos dos clubes que foram estatisticamente } \\
\text { significativas, sendo que a primeira variável qualitativa } \\
\text { refere-se ao Brasil e a segunda (quando for o caso), à Argentina. } \\
\text { Os resultados para todas as dummies de clube encontram-se na } \\
\text { Tabela } 5 \text { no Apêndice. }\end{array}$} \\
\hline
\end{tabular}


porque, enquanto o investimento no elenco de uma equipe com performance baixa ou média, a qual geralmente está associada à limitação técnica dos jogadores, pode facilmente melhorar tal desempenho, é mais difícil aumentar a qualidade técnica do elenco e continuar dessa forma, elevando o aproveitamento continuamente de um clube, comprando jogadores mais caros quando essa equipe torna-se cada vez mais qualificada. Nesse sentido, o maior VM médio do Brasil faz com que essa limitação do impacto do VM seja vislumbrada, o que não aconteceu para o caso argentino.

A constatação de que o valor de mercado médio do jogador de uma equipe, obtido a partir das qualidades técnicas e características dos atletas do elenco, influencia o desempenho final da mesma na competição, está em consonância com os resultados encontrados por Gerhards \& Mutz (2017) para as 12 principais ligas europeias. Dessa forma, conforme o esperado, quanto maior o $V M$, mais qualificados tendem a ser os jogadores de equipe e, por consequência, mantidas as demais variáveis constantes, maior a probabilidade dessa equipe terminar o campeonato com aproveitamento alto em termos de pontos conquistados. A título de ilustração, observa-se que essa parece ser a tendência no campeonato brasileiro, haja vista que, em 2018, a equipe com o maior gasto em termos de remuneração total dos jogadores do elenco (Palmeiras) foi a vencedora ${ }^{4}$ Já em 2019, após o término do primeiro turno do campeonato brasileiro, os três primeiros colocados (Flamengo, Palmeiras e Santos), conforme Transfermarkt (2019), eram exatamente as três equipes com os maiores valores de mercado dos elencos.

Passando para a variável Treinador, a mesma foi estatisticamente significativa como determinante negativo do desempenho dos clubes nas ligas de Brasil e Argentina. Com relação ao Brasil, o aumento em um desvio padrão da média de treinadores por equipe leva a redução em 3,7 pp no aproveitamento final da equipe. Já na Argentina, este aumento em um desvio acarreta em perda de 4,4 pp no aproveitamento. Considerando a média amostral de treinadores por equipe na temporada de 2,70 e desvio de 0,16 para o Brasil e média de 1,92 e desvio de 0,21 para a Argentina, observa-se que mesmo tendo em média uma troca de comando a mais na temporada no Brasil do que na Argentina, o impacto no desempenho médio final é menor para o caso brasileiro. Isto pode estar ligado ao fato de que na maior parte da amostra do futebol argentino, considerou-se apenas o torneio Apertura, que é uma competição de curta duração equivalente ao primeiro turno do campeonato brasileiro. Logo, acredita-se que por este motivo, o impacto negativo da mudança de técnico ao longo da temporada é maior na Argentina, uma vez que o tempo de adaptação para o novo técnico na liga argentina antes do término da competição é comparativamente menor. Ainda sobre a variável Treinador, destaca-se que pequena alteração no seu valor provoca impacto negativo no desempenho da equipe nos dois campeonatos considerados, ressaltando a importância da realização de um planejamento de longo prazo com o mesmo técnico para o êxito da equipe nas competições. Confirmando esse ponto, pode-se citar o caso do River Plate, comandado desde 2014 pelo técnico Marcelo Gallardo. Com base em Ceconello (2019), nesse período de cinco anos o treinador tornou-se aquele com o maior número de títulos na história do clube (dez), incluindo conquis-

\footnotetext{
${ }^{4}$ Conforme dados do balanço financeiro do clube, disponível em Capelo (2019), o Palmeiras gastou R $\$ 255$ milhões de reais em 2018 com a remuneração total de jogadores (salários, direitos de imagem e direitos de arena do futebol profissional).
} 
tas continentais importantes como duas Taças Libertadores da América (2015 e 2018) e uma Copa Sul-Americana (2014).

A quantidade de jogos simultâneos à liga nacional e sua forma quadrática foram significativos apenas para o campeonato argentino, de modo que o aumento em 1 desvio padrão deste fator eleva o aproveitamento final na liga, na média, em 2,4 pp, mantendo os outros fatores constantes. Sabendo que a média amostral desta variável para Argentina é de 4,61 jogos e o desvio de 1,25, então a elevação da média de 4,61 para 5,86 jogos ocasionaria o referido aumento do aproveitamento ao final da competição. No entanto, como a forma quadrática da variável também foi significativa, existe limiar no qual caso a equipe faça certa quantidade de jogos a mais em outra competição, estas partidas simultâneas prejudicariam o desempenho da equipe na liga.

Entende-se então que, no futebol argentino, participar das copas pode representar maior confiança e segurança do elenco, o que gera impactos positivos na disputa nacional. Porém, na medida em que a equipe vai avançando de fase nas copas, uma vez que o elenco é o mesmo, geralmente os treinadores utilizam reservas nas ligas nacionais. Ademais, pode haver desgaste físico da equipe, caso não haja esse rodízio de jogadores, ou até mesmo psicológico, no caso de uma eliminação, fazendo com que, assim, o desempenho seja prejudicado ao final do campeonato nacional. Novamente o River Plate pode ser citado para ilustrar tal efeito, já que, entre os dez títulos conquistados pela equipe durante o período do treinador Marcelo Gallardo (2014-atual), não há nenhum campeonato argentino.

Já para o caso brasileiro, a variável Qjogos não se mostrou significativa, o que vai ao encontro do estudo de Audas et al. (2002). Os autores, ao analisarem os impactos do desempenho dos times na FA Cup (torneio semelhante à Copa do Brasil e Copa da Argentina) em relação à Premier League da Inglaterra, mencionam que a eliminação precoce na copa pode trazer resultados ambíguos quanto ao desempenho na liga. Isto porque um time eliminado na copa pode concentrar toda a atenção na liga e, assim, há a possibilidade de melhora do performance no campeonato ainda em disputa. Contudo, a eliminação pode gerar perda de confiança, causando uma piora do desempenho na liga, da mesma forma que o não avanço para fases subsequentes pode evitar o desgaste do elenco com a realização de mais jogos da equipe, fazendo com que a mesma melhore seu aproveitamento na competição que ainda resta. Resultados semelhantes foram encontrados por Guzmán \& Morrow (2007) em um estudo sobre produtividade dos clubes na Premier League inglesa, ao relacionar a quantidade de jogos nas competições europeias com a produtividade dos times na liga nacional.

Em relação às dummies de efeitos fixos dos clubes, para o caso brasileiro, verificou-se que as equipes agrupadas nas variáveis DNE, DSUL e DOUT, apresentaram, em média, desempenho inferior aos demais clubes considerados na amostra. Esse resultado era esperado, uma vez que essas três dummies citadas englobam equipes, em geral, com menores torcidas e receitas do que as demais, impactando, dessa forma, em desempenho comparativamente inferior em termos de aproveitamento de pontos. Sobre os clubes do Nordeste (DNE), destaca-se ainda a questão geográfica. Isso porque, como a maioria das equipes do campeonato brasileiro concentram-se nas regiões Sudeste e Sul, as do Nordeste precisam se deslocar relativamente mais para a disputa dos jogos, o que pode ocasionar maior desgaste dos seus elencos. Em termos de efeitos marginais, os desempenhos das equipes agrupadas nas variáveis DNE, DSUL 
e DOUT foram, respectivamente, de $-5,2$ pp, $-4,9$ pp e - $-8,8$ pp em relação aos demais clubes.

Já para a Argentina, verificou-se que as equipes consideradas nas dummies DBA e DFBA apresentaram aproveitamento de -9,8 pp e -9,2 pp, respectivamente, em comparação às demais. Esse resultado era esperado, já que essas variáveis englobam, de maneira geral, clubes com menores receitas, torcidas e títulos do que os restantes.

Ao contrário do que se esperava, as variáveis CVE, Estrangeiro, Flutuação, CVI e Série $B$ não se mostraram significativas para predizer o desempenho em nenhum dos modelos regredidos. Sendo assim, a análise daqui em diante se concentra na explicação da não significância dessas variáveis.

Assim como constatado por Gerhards \& Mutz (2017), o CVE não foi estatisticamente relevante para nenhuma das duas ligas. Este fator pode não ter impactado significativamente no aproveitamento porque, devido à constante exportação de jogadores para a Europa, existe no futebol da América do Sul a cultura de aproveitar atletas da base no elenco principal. Esses jogadores recém-chegados ao profissional usam os atletas mais experientes do elenco como exemplo (atletas que geralmente apresentam valor de mercado e salários mais elevados), os quais motivam os mais jovens a melhorar seu desempenho individual a ponto de um dia poderem chegar ao mesmo patamar salarial desses jogadores mais experientes. Portanto, esse tipo de diferença salarial que se reflete em maior CVE não impactaria negativamente na coesão do grupo, não prejudicando, consequentemente, o aproveitamento na competição.

No mesmo sentido, Tao et al. (2016) evidenciam que a desarmonia tende a ser maior em equipes cujos salários são elevados para todo o elenco e não nos times onde os grandes salários são minoria. Traçando um paralelo com o futebol da América do Sul, sabe-se que a maioria dos times tem uma estrutura de valor de mercado onde poucos jogadores do plantel possuem grande valor de mercado. Levando em conta que nesta variável, quanto mais próximo de 0 , menor é a desigualdade de valor de mercado dentro do elenco, observouse que $85 \%$ dos clubes da amostra tem $C V E$ superior a 0,5. Logo, infere-se que, dentro da realidade do futebol sul-americano, a desproporção de valor de mercado é algo comum e, por isso, a variável não foi relevante, já que os desvios atingiram, em relação à média do $V M$, mais do que $50 \%$ do valor desta em $85 \%$ das observações.

Em relação à não significância estatística da variável Estrangeiro, destacase que, de maneira similar ao presente trabalho, Brandes et al. (2009), em seu estudo sobre o campeonato alemão, não encontraram correlação entre diversidade cultural e sucesso no campeonato. Os autores justificaram tal achado pelo fato de entenderem que a produção individual do atleta estrangeiro não seria relevante a ponto de impactar na produção em equipe. Logo, o conjunto prevaleceria sobre o individual e, assim, o impacto das características do jogador estrangeiro seria reduzido.

A flutuação dos elencos foi outro aspecto que não se mostrou significativo no desempenho para as competições estudadas, assim como encontrado por Gerhards \& Mutz (2017) para as ligas europeias. Para o caso sul-americano, é importante destacar que, em função de os clubes terem menos recursos financeiros em relação a equipes de outros mercados, como o europeu por exemplo, é comum que os jogadores que se destacam nos campeonatos brasileiro e argentino sejam logo vendidos para os referidos mercados. Dessa forma, a vari- 
ação constante do elencos é algo comum nas ligas estudadas e, talvez por isso, o seu impacto no aproveitamento nas mesmas não tenha sido significativo.

Outro fator relacionado ao elenco que não foi significativo foi o coeficiente de variação da idade do mesmo. Como já constatado pela análise descritiva, a idade média dos elencos variou muito pouco entre os elencos e entre os anos da amostra, indicando a existência de homogeneidade etária dos atletas em todos os clubes. Logo, levando em consideração esta semelhança entre os plantéis, acredita-se que isto faz com que, isoladamente, o CVI do elenco não seja crucial para explicar o sucesso na liga nacional. Como já exposto, existe uma faixa etária mais adequada para a prática do futebol em alto nível e, dessa forma, isto torna essa variável mais homogênea entre os times, tornando seu impacto econométrico irrelevante.

Por fim, têm-se que a dummy para os clubes recém promovidos, assim como as demais variáveis mencionadas anteriormente, também não foi significativa. No caso brasileiro, a não significância pode residir no fato de que no país, por exemplo, considerando 2006 em diante, 70\% dos times que subiram se mantiveram na primeira divisão, sendo tal porcentagem de $95 \%$ na liga argentina. Este resultado diverge dos encontrados por Frick \& Simmons (2008) para o campeonato alemão e por Carmichael et al. (2011) para a Premier League inglesa, os quais mostraram que o desempenho dos times recém-chegados à divisão de elite é pior do que o dos já estabelecidos.

\section{Considerações finais}

Usando como suporte o trabalho de Gerhards \& Mutz (2017), que identificou os determinantes do aproveitamento, em termos de pontos totais, nas principais ligas europeias, este estudo tratou de responder à mesma questão, adaptando tal pesquisa ao caso sul-americano, utilizando para tal as ligas nacionais de Brasil e Argentina.

Em termos do comportamento dos determinantes considerados no período 2006-2017, verificou-se que o campeonato brasileiro, em comparação ao argentino, apresentou maior valor de mercado médio dos jogadores, flutuação nos elencos, número de treinadores por equipe durante o campeonato e números de jogos ao longo da temporada. Especificamente, destacaram-se no Brasil o aumento do número de estrangeiros nos clubes ao longo do período estudado, enquanto que, na na Argentina, ressaltou-se as constantes mudanças de formato e número de equipes participantes na competição a partir de 2014.

Os resultados econométricos mostraram que, na comparação entre as duas ligas, observou-se que o valor de mercado e número de treinadores tiveram impacto em ambas as competições. Isoladamente, a forma não-linear do valor de mercado teve significância apenas para o modelo brasileiro e a quantidade de jogos simultâneos foi relevante somente no modelo argentino.

Confirmando a hipótese central deste artigo, o valor de mercado foi estatisticamente significativo nos dois modelos. Isto pode estar relacionado ao fato de que, como os valores monetários das transferências são uma medida de qualidade dos jogadores, logo, quanto maior o $V M$ médio dos atletas do elenco, maior é a qualidade técnica do time e, portanto, melhor tende a ser o aproveitamento ao final do campeonato local.

De maneira geral, entende-se que os resultados desta pesquisa podem colaborar para que os clubes possam utilizar melhor seus recursos, de modo a 
melhorar o aproveitamento na liga nacional, pois esta melhora pode trazer inúmeros benefícios à instituição. Sabe-se que aprimorar o desempenho na liga traz benesses financeiras para o clube, já que bom desempenho no campeonato acarreta em boa visibilidade no mercado de investidores e aumento da confiança de seus adeptos. Isso faz com que o time incorra em ganhos em suas receitas através do aumento de patrocínios e número de sócio-torcedores. Esse aumento na receita possibilita à equipe se estruturar melhor e, até mesmo, fazer contratações que possam agregar ainda mais qualidade técnica ao time e, dessa forma, gera-se um círculo virtuoso de sucesso.

Portanto, a qualidade técnica do elenco, medida através do valor de mercado médio dos jogadores das equipes, juntamente com a manutenção do mesmo treinador ao longo de todo o campeonato, mostraram ser variáveischave para o desempenho das equipes nas competições, de forma que os gestores dos clubes devem ficar atentos a tais fatores quando do planejamento para as respectivas competições.

Sugere-se, para pesquisas futuras, a ampliação dos determinantes considerados no estudo, de forma a medir o impacto de outras variáveis no desempenho final das equipes, tais como aspectos financeiros dos clubes, como receitas e despesas, e a qualidade da gestão praticada na instituição, como acúmulo de dívidas e atraso de salários.

\section{Referências Bibliográficas}

Aidar, A. C. K. \& Faulin, E. J. (2013), 'O negócio do futebol', Caderno FGV Projetos 8(22), 46-61.

Araujo Jr, A. F., Shikida, C. D. \& Ferreira, V. G. (2018), 'Determinantes das mudanças de liderança: o caso do campeonato brasileiro de futebol', RBFFRevista Brasileira de Futsal e Futebol 10(37), 130-137.

Araújo Jr, A. F., Shikida, C. D. \& Monasterio, L. M. (2005), 'Uma análise econométrica do futebol brasileiro', Análise Econômica 23(44), 217-240.

Audas, R., Dobson, S. \& Goddard, J. (2002), 'The impact of managerial change on team performance in professional sports', Journal of Economics and Business 54(6), 633-650.

Bonsanti, B. (2017), 'Fox e turner compram direitos do argentino (quase) pelo dobro do que pagava o governo'. http://m.trivela.uol.com.br/ fox-e-turner-compram-direitos-do-argentino-quase-pelo-dobro-do-que-pa gava-o-governo/; Trivela; Acesso em 21 de dezembro de 2018.

Brandes, L., Franck, E. \& Theiler, P. (2009), 'The effect from national diversity on team production-empirical evidence from the sports industry', Schmalenbach Business Review 61(2), 225-246.

Cameron, A. C. \& Trivedi, P. K. (2005), Microeconometrics: methods and applications, Cambridge: Cambridge University Press.

Capelo, R. (2019), 'Dinheiro compra título? eis a lista dos clubes mais eficientes do futebol brasileiro em 2018.'. https://globoesporte.globo.com/blogs/ blog-do-rodrigo-capelo/post/2019/07/12/dinheiro-compra-titulos-eis-alista-dos-clubes-mais-eficientes-do-futebol-brasileiro-em-2018.ghtml; Globoesporte.com; Acesso em 23 de setembro de 2019. 
Carmichael, F., McHale, I. \& Thomas, D. (2011), 'Maintaining market position: team performance, revenue and wage expenditure in the English premier league', Bulletin of Economic Research 63(4), 464-497.

Ceconello, D. (2019), 'A Era Gallardo'. https://globoesporte.globo. com/blogs/meia-encarnada/post/2019/05/31/a-era-gallardo.ghtml; Globoesporte.com; Acesso em 04 de outubro de 2019.

Cicciaro, I. \& Puccio, X. (2010), 'La pasión del hincha de un equipo del fútbol argentino', Creación y Producción en Diseño y Comunicación p. 49.

Conmebol (2013), '265 milhões de pessoas jogam futebol no mundo inteiro.'. http://www.conmebol.com/pt-br/content/ 265-milhoes-de-pessoas-jogam-futebol-no-mundo-inteiro; Confederación Sudamericana de Fútbol; Acesso em 21 de dezembro de 2018.

Coremberg, A., Sanguinetti, J. \& Wierny, M. (2015), 'La contribución del fútbol a la economía argentina'.

Cribari Neto, F. \& Vasconcellos, K. L. (2002), 'Nearly unbiased maximum likelihood estimation for the beta distribution', Journal of Statistical Computation and Simulation 72(2), 107-118.

Daolio, J. (2000), 'As contradições do futebol brasileiro', Futebol: paixão e política. Rio de Janeiro: DPEA pp. 29-44.

Drummond, L., Júnior, A. A. \& Shikida, C. (2010), 'Campeonato brasileiro de futebol e balanço competitivo: uma análise do período 1971-2009', Revista Brasileira de Futebol (The Brazilian Journal of Soccer Science) 3(2), 73-87.

EUROSTAT (2019), 'Harmonized indices of consumer prices (hicp)'. https://ec.europa.eu/eurostat/web/hicp/data/database?p_p_ id=NavTreeportletprod_WAR_NavTreeportletprod_INSTANCE_B06F gp25CkI9\& p_p_lifecycle=0\&p_p_state=normal\&p_p_mode=view\&p_p_col_id=column-2\&p_ p_col_count=3\&fbclid=IwAR1SfpSULBXsTMXDKHOP6hIBrHw3D jFaUv1EMWMHwG19_ phzwDa77nsGGaE; Acesso em 22 de maio de 2019.

Ferrari, S. \& Cribari Neto, F. (2004), 'Beta regression for modelling rates and proportions', Journal of applied statistics 31(7), 799-815.

Footballdatabase (2017). https://www. footballdatabase.eu/fr/; Acesso em 01 de junho de 2017.

Footstats (2017). http://meu.footstats.net/; Acesso em 01 de junho de 2017.

Fort, R. \& Quirk, J. (2004), 'Owner objectives and competitive balance', Journal of Sports Economics 5(1), 20-32.

Frick, B. \& Simmons, R. (2008), 'The impact of managerial quality on organizational performance: evidence from German soccer', Managerial and Decision Economics 29(7), 593-600. 
Gammaro, V. (2017), 'Campeonato brasileiro bate recorde de jogadores estrangeiros'. https://www.df.superesportes.com.br/app/noticias/ futebol/futebol-nacional/2017/07/18/noticia_futebol_nacional,61988/ recorde-jogadores-estrange iros-brasileirao.shtml; SuperEsportes; Acesso em 18 de julho de 2017.

Gasparetto, T. \& Barajas, A. (2016), 'Reanalizando la competitividad en la industria del fútbol: diferencia acumulada de puntos', Revista de Administração de Empresas 56(3), 288-301.

Gerhards, J. \& Mutz, M. (2017), 'Who wins the championship? Market value and team composition as predictors of success in the top European football leagues', European Societies 19(3), 223-242.

Gil, G. J. (2003), 'La modernización imaginada del fútbol argentino: entre el club y la empresa', Civitas-Revista de Ciências Sociais 3(2), 339-348.

Giovanaz, D. (2017), 'Macri privatiza direitos de transmissão do futebol na Argentina'. https://www.brasildefato.com.br/2017/02/16/ macri-privatiza-direitos-de-transmissao-do-futebol-na-argentina/; Brasil de Fato; Acesso em 16 de fevereiro de 2017.

Giovannetti, B., Rocha, B. P., Sanches, F. M. \& Silva, J. C. D. (2006), 'Medindo a fidelidade das torcidas brasileiras: uma análise econômica no futebol', $R e$ vista Brasileira de Economia 60(4), 389-406.

Gonçalves, E. (2016), 'Quanto tempo “dura” o treinador nas cinco grandes ligas... e no Brasil'. http://globoesporte. globo.com/blogs/especial-blog/olhar-cronico-esportivo/post/ quanto-tempo-dura-o-treinador-nas-cinco-grandes-ligas-e-no-brasil; Globoesporte.com; Acesso em 07 de junho de 2017.

Guedes, S. L. (2014), 'On criollos and capoeiras: notes on soccer and national identity in Argentina and in Brazil', Soccer E Society 15(1), 147-161.

Guma, J. P. (2015), 'Os 50 melhores treinadores do mundo: oito sul-americanos e, óbvio, nenhum brasileiro'. https://www. torcedores.com/noticias/2015/07/ os-50-melhores-treinadores-do-mundo-oito-sul-americanos-e-obvio-nenhu m-brasileiro; Torcedores.com; Acesso em 02 de fevereiro de 2018.

Guzmán, I. \& Morrow, S. (2007), 'Measuring efficiency and productivity in professional football teams: evidence from the English Premier League', Central European Journal of Operations Research 15(4), 309-328.

Hoffmann, R., Ging, L. C. \& Ramasamy, B. (2002), 'The socio-economic determinants of international soccer performance', Journal of Applied Economics 5(2), 253-272.

Jones, J. C. (1969), 'The economics of the national hockey league', The Canadian Journal of Economics/Revue canadienne d'Economique 2(1), 1-20.

Késenne, S. (2006), 'The win maximization model reconsidered: Flexible talent supply and efficiency wages', Journal of Sports Economics 7(4), 416-427. 
Madalozzo, R. \& Villar, B. R. (2009), 'Brazilian football: what brings fans to the game?', Journal of Sports Economics 10(6), 639-650.

Mena, F. C. (2009), 'La crisis del fútbol argentino'. https://works.bepress. com/fernando_carrion/335/; Diario Hoy; Acesso em 07 de fevereiro de 2018.

Neale, W. C. (1964), 'The peculiar economics of professional sports', The quarterly journal of economics 78(1), 1-14.

oGol (2017). https://www.ogol.com.br/; Acesso em 3 de fevereiro de 2017.

Palomino, F., Rigotti, L., Rustichini, A. et al. (1998), Skill, strategy and passion: An empirical analysis of soccer, Tilburg University.

Papanikos, G. T. (2017), 'Economic, population and political determinants of the 2014 World Cup match results', Soccer E Society 18(4), 516-532.

Pluri Consultoria (2012), 'O PIB do esporte brasileiro'. Curitiba: Pluri Consultoria, $15 \mathrm{p}$.

Pluri Consultoria (2014a), O círculo virtuoso de um clube de futebol. Curitiba: Pluri Consultoria, $7 \mathrm{p}$.

Pluri Consultoria (2014b), Os 25 campeonatos nacionais mais valiosos do mundo. Curitiba: Pluri Consultoria, 7 p.

Ribeiro, A. S. \& Lima, F. (2012), 'Portuguese football league efficiency and players' wages', Applied Economics Letters 19(6), 599-602.

Rottenberg, S. (1956), 'The baseball players' labor market', Journal of political economy 64(3), 242-258.

Shikida, C., Carraro, A. \& Júnior, A. F. A. (2018), 'O mando de campo em clássicos: os casos bra-pel e gre-nal', Análise Econômica 36(71), 135-164.

Shikida, C. D., Araujo Jr, A. F. \& Pinho, F. M. (2018), 'Cartões vermelhos e amarelos e a teoria econômica do crime: o caso do campeonato brasileiro de futebol', Economic Analysis of Law Review 9(1), 242-258.

Sloane, P. J. (1971), 'The economics of professional football: the football club as a utility maximiser', Scottish journal of political economy 18(2), 121-146.

Smithson, M. \& Verkuilen, J. (2006), 'A better lemon squeezer? maximumlikelihood regression with beta-distributed dependent variables.', Psychological methods 11(1), 54 .

Tao, Y.-L., Chuang, H.-L. \& Lin, E. S. (2016), 'Compensation and performance in major league baseball: Evidence from salary dispersion and team performance', International Review of Economics E Finance 43, 151-159.

Transfermarkt (2019). https: / / www. transfermarkt.pt/; Acesso em 22 de abril de 2019.

Trejo, S. M. F., Murzi, D. \& Nassar, B. (2019), 'Violence and death in Argentinean soccer in the new Millennium: Who is involved and what is at stake?', International Review for the Sociology of Sport . 54(7), 1-18. 


\section{Apêndice}

Tabela 5: Dummies para os efeitos fixos dos clubes como determinantes do desempenho, em termos de aproveitamento percentual dos pontos conquistados, ao final dos campeonatos brasileiro e argentino de $\mathrm{fu}-$ tebol, $2006-2017$

\begin{tabular}{|c|c|c|}
\hline Aproveitamento & Brasil & Argentina \\
\hline DSP / DRIV & $\begin{array}{l}0,135 \\
(0,079)\end{array}$ & $\begin{array}{r}-0,247 \\
(0,015)\end{array}$ \\
\hline DCOR / DRAC & $\begin{array}{l}0,012 \\
(0,086)\end{array}$ & $\begin{array}{r}-0,069 \\
(0,135)\end{array}$ \\
\hline DSAN / DSL & $\begin{array}{r}-0,080 \\
(0,064)\end{array}$ & $\begin{array}{r}-0,109 \\
(0,141)\end{array}$ \\
\hline DPAL / DIND & $\begin{array}{r}-0,014 \\
(0,095)\end{array}$ & $\begin{array}{r}-0,130 \\
(0,172)\end{array}$ \\
\hline DVAS / DVEL & $\begin{array}{l}0,031 \\
(0,076)\end{array}$ & $\begin{array}{r}-0,128 \\
(0,136)\end{array}$ \\
\hline DFLU / DEST & $\begin{array}{r}-0,012 \\
(0,080)\end{array}$ & $\begin{array}{l}0,067 \\
(0,145)\end{array}$ \\
\hline DBOT / DLB & $\begin{array}{r}-0,130 \\
(0,068)\end{array}$ & $\begin{array}{r}-0,142 \\
(0,140)\end{array}$ \\
\hline DCRU / DROS & $\begin{array}{l}0,057 \\
(0,071)\end{array}$ & $\begin{array}{r}-0,130 \\
(0,137)\end{array}$ \\
\hline DCAM & $\begin{array}{r}-0,056 \\
(0,072)\end{array}$ & - \\
\hline DGRE & $\begin{array}{l}0,054 \\
(0,085)\end{array}$ & - \\
\hline DINT & $\begin{array}{r}-0,014 \\
(0,075)\end{array}$ & - \\
\hline DNE / DBA & $\begin{array}{c}-0,148^{* *} \\
(0,064)\end{array}$ & $\begin{array}{c}-0,306^{* *} \\
(0,132)\end{array}$ \\
\hline DCUR & $\begin{array}{l}0,015 \\
(0,063)\end{array}$ & - \\
\hline DSUL / DFBA & $\begin{array}{c}-0,138^{* *} \\
(0,070)\end{array}$ & $\begin{array}{c}-0,286^{* *} \\
(0,130)\end{array}$ \\
\hline $\mathrm{DCO}$ & $\begin{array}{r}-0,108 \\
(0,078)\end{array}$ & - \\
\hline DOUT & $\begin{array}{c}-0,249^{* * * *} \\
(0,072)\end{array}$ & - \\
\hline Observações & 240 & 270 \\
\hline Wald qui-quadrado & $339,99^{* * *}$ & $210,62^{* * *}$ \\
\hline \multicolumn{3}{|c|}{$\begin{array}{l}\text { Fonte: Elaboração própria } \\
\text { Notas: } \\
*_{* * *} \text { significativo a } 1 \% .{ }^{* *} \text { significativo a } 5 \% . \\
\text { Na Tabela } 5 \text {, a primeira variável qualitativa }\end{array}$} \\
\hline
\end{tabular}

